\title{
Non-negative least squares computation for in vivo myelin mapping using simulated multi-echo spin-echo $\mathbf{T}_{2}$ decay data
}

\author{
Vanessa Wiggermann ${ }^{1,2, a}$, Irene Vavasour ${ }^{3,4}$, Shannon Kolind ${ }^{1,3,5}$, Alex MacKay ${ }^{1,3,4}$, Gunther Helms $^{6, *}$, and Alexander \\ Rauscher $^{1,2,3,4, *}$ \\ ${ }^{1}$ Department of Physics and Astronomy, University of British Columbia; ${ }^{2}$ Department of Pediatrics, University of British Columbia; ${ }^{3}$ UBC MRI Research Centre, University of \\ British Columbia; ${ }^{4}$ Department of Radiology, University of British Columbia; ${ }^{5}$ Department of Medicine, University of British Columbia; ${ }^{6}$ Department of Clinical Sciences Lund, \\ Lund University; ${ }^{*}$ equal contribution \\ A revised version of this manuscript was accepted for publication in NMR in Biomedicine.
}

\begin{abstract}
Multi-compartment $\mathbf{T}_{2}$-mapping has gained particular relevance for the study of myelin water in brain. As a facilitator of rapid saltatory axonal signal transmission, myelin is a cornerstone indicator of white matter development and function. Regularized non-negative least squares fitting of multi-echo $\mathrm{T}_{2}$ data has been widely employed for the computation of the myelin water fraction (MWF) and the obtained MWF maps have been histopathologically validated. MWF measurements depend upon the quality of the data acquisition, $\mathrm{B1}^{+}$homogeneity and a range of fitting parameters. In this special issue article, we discuss the relevance of these factors for the accurate computation of multi-compartment $\mathrm{T}_{2}$ and MWF maps. We generated multi-echo spin-echo $\mathrm{T}_{2}$ decay curves following the approach of CarrPurcell-Meiboom-Gill for various myelin concentrations and myelin $\mathbf{T}_{2}$ scenarios by simulating the evolution of the magnetization vector between echoes based on the Bloch equations. We demonstrated that noise and imperfect refocusing flip angles yield systematic underestimations in MWF and intra-/extracellular water geometric mean (gm) $\mathbf{T}_{2}$. MWF estimates were more stable than myelin water $\mathbf{g m T}_{2}$ time across different settings of the $T_{2}$ analysis. We observed that the lower limit of the $\mathbf{T}_{2}$ distribution grid should be slightly shorter than TE1. Both TE1 and the acquisition echo spacing also have to be sufficiently short to capture the rapidly decaying myelin water $\mathbf{T}_{2}$ signal. Among all parameters of interest, the estimated MWF and intra/extracellular water gmT $_{2}$ differed by approximately $\mathbf{0 . 1 3 - 4}$ percentage points and 3-4 ms, respectively, from the true values, with larger deviations observed in the presence of greater $\mathrm{B} 1^{+}$-inhomogeneities and at lower signal-to-noise ratio. Tailoring acquisition strategies may allow to better characterize the $\mathbf{T}_{2}$ distribution, including the myelin water, in vivo.
\end{abstract}

myelin $\mid \mathrm{T}_{2}$ distribution $\mid \mathrm{T}_{2}$ decay $\mid$ relaxation $\mid$ non-negative lease squares | flip angles | noise | spin echo

$\mathbf{S}$ ince the inception of magnetic resonance imaging (MRI), researchers have strived to use MR signal relaxation techniques for the characterization of tissues and tissue pathologies. $\mathrm{T}_{2}$-weighting by means of spin-echoes, first described by Erwin Hahn $[1,2]$, captures the effect of random field fluctuations on the transverse $\mathrm{MR}$ signal. Quantitative $\mathrm{T}_{2}$ relaxation measurements are commonly performed using the Carr-Purcell-Meiboom-Gill (CPMG) acquisition scheme [3,4]. Rapid acquisitions or 3D encoding utilize a "train" of spinechoes, a technique pioneered by Jürgen Hennig [5]. Hennig also devised the extended phase graph (EPG), used to describe the formation of spurious echoes in the $\mathrm{T}_{2}$ decay due to imperfect refocusing flip angles (FA) in the presence of static field inhomogeneities $[6,7]$. By ensuring that subsequent refocusing pulses have the same phase, orthogonal to that of the excitation pulse, CPMG mitigates errors due to imperfect refocusing and achieves higher signal through constructive interference of refocusing pathways. $\mathrm{T}_{2}$-mapping has been primarily applied to characterize brain tissue $[8,9]$, but also outside the brain for imaging of cartilage [10] and intervertebral discs [11]. Notably, microstructural tissue compartmentalization can contribute more than one exponential component to the $\mathrm{T}_{2}$ decay [12-15].

The short $\mathrm{T}_{2}$ component in the brain and its relationship with myelin Multi-component analysis of multi-echo $\mathrm{T}_{2}$ data through construction of continuous $\mathrm{T}_{2}$ distributions was described by Whittall and MacKay [16]. They employed nonnegative least squares (NNLS) [17] to solve the inverse problem that is posed by an unknown number of $\mathrm{T}_{2}$ components contributing to the $\mathrm{T}_{2}$ decay. In the early nineties, Menon and Allen [18] described two $\mathrm{T}_{2}$ components in feline brain ex vivo and assigned the shorter component to water in myelin. Thereafter, a similar $\mathrm{T}_{2}$ component was observed in guinea pig brain ex vivo [13]. MacKay and Whittall et al. were the first to report a short $\mathrm{T}_{2}$ component in human brain in vivo at 1.5 $\mathrm{T}$ [19]. This short $\mathrm{T}_{2}$ signal co-localized with brain white matter (WM) and its signal proportion was in line with the amounts of "myelin water" (MW) reported in vitro [20]. These observations strongly suggested that the short $\mathrm{T}_{2}$ signal originates from water molecules trapped within the tightly wrapped myelin bilayers. At $30 \AA$ [21], i.e. only about ten times the size of water molecules, the space occupied by water within the bilayers is much narrower than intra- and inter-axonal distances. The therefore restricted motion leads to faster spinspin dephasing of aqueous protons in MW than in the intraand extracellular space. The MR signal from non-aqueous protons of the phospholipid bilayers decays to zero in less than $100 \mu \mathrm{s}$; hence it is not visible with conventional MR systems [22]. The relationship of the short $\mathrm{T}_{2}$ component and myelin was illustrated in cases of known myelin pathology, where lesions devoid of myelin showed little short $\mathrm{T}_{2}$ signal [23,24]. Histopathological studies later validated the association of the short $\mathrm{T}_{2}$ component with myelin lipid concentrations $[25,26]$. The term myelin water fraction (MWF) was coined for the short $T_{2}$ fraction of the total water signal. However, water protons other than those in myelin may contribute to rapid $\mathrm{T}_{2}$ decay. Biological iron, calcium and other tissue constituents can cause additional $\mathrm{T}_{2}$ shortening of water signal in the intra-

The authors have no conflicts of interest to declare.

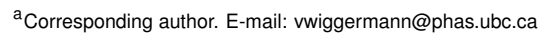


and extracellular space [27], increasing the apparent MWF [28]. Since WM iron is predominantly found in myelin forming oligodendrocytes and contributes to lipid synthesis [29], the sensitivity of the short $\mathrm{T}_{2}$ component to both myelin and iron should be considered. Mapping myelin in vivo permits us to study brain development [30-32], trauma [33] or aging [34,35], as well as neurodegenerative diseases that have a direct link to myelination, such as multiple sclerosis (MS) [23,36]. However, despite being proposed 25 years ago, spin-echo myelin water imaging (MWI) has to-date found limited clinical application. This is in part due to the long acquisition times and an intricate signal analysis.

MWI using non-negative least squares (NNLS) fitting to multi-exponential $\mathrm{T}_{2}$ data The NNLS analysis and the computation of the MWF depend on a number of parameters. In vivo literature has primarily reported on multi-component $\mathrm{T}_{2}$-mapping and corresponding analysis parameters in human brain at $1.5 \mathrm{~T}$ and $3 \mathrm{~T}$. As MWI expands to other field strengths and applications for which multi-component $\mathrm{T}_{2}$ times have not yet been established, adjustment of the $\mathrm{T}_{2}$ analysis and application of NNLS may be required to obtain reliable MWF measurements. For example, if $\mathrm{T}_{2}$ relaxation times are shorter, the $T_{2}$ boundaries that distinguish the different water compartments need to be redefined. Otherwise, signal from a water pool with a $\mathrm{T}_{2}$ longer than that of MW may be erroneously counted toward the short water pool fraction as it crosses the pre-established $\mathrm{T}_{2}$ cut-off [37]. In brain tissues, the intermediate water compartment is attributed to intraand extracellular water (IEW). This intermediate $\mathrm{T}_{2}$ pool can typically not be further divided using the resolution of $\mathrm{T}_{2}$ time at $3 \mathrm{~T}$. However, a few studies have found two $\mathrm{T}_{2}$ times in the intermediate $\mathrm{T}_{2}$ range, ascribing the longer component to extracellular water [38-40].

To provide greater insight into the data analysis, we discuss in this article the various parameters involved in the computation of the NNLS solution [17] in accurately determining different water pool fractions and their $\mathrm{T}_{2}$ properties. A number of groups have assessed the properties of NNLS for multi-component $\mathrm{T}_{2}$ analysis, particularly in the first decade of MWI [16,41,42-44]. We intend to update those findings and provide a guideline for the application of NNLS with EPG to multi-component $T_{2}$ analysis in different settings. The main challenge for testing analysis parameters in vivo relates to the lack of a known ground truth. The MWF and even more so the $\mathrm{T}_{2}$ of myelin water $(\mathrm{MW})$ are not well established. Differences in acquisition timing may further influence the range of $\mathrm{T}_{2}$ time that is accessible for analysis of $\mathrm{T}_{2}$ decay data [41]. In this work, we used Bloch simulations to generate signal decay curves from different multi-echo $\mathrm{T}_{2}$ acquisition strategies for synthetic voxels that contained realistic myelin geometries. First, the EPG algorithm was employed to estimate the unknown refocusing FAs $[7,45]$. Thereafter, the generated $\mathrm{T}_{2}$ decay curves were analyzed with varying NNLS parameters and results were compared to the known ground truth. We addressed the influence of noise and regularization on the computation, in scenarios of low to high MWFs and different $\mathrm{MW} \mathrm{T}_{2}$ times.

\section{Experimental}

Numerical simulation of T2 decay data. Bloch simulations were performed on a 256 x 256 grid over

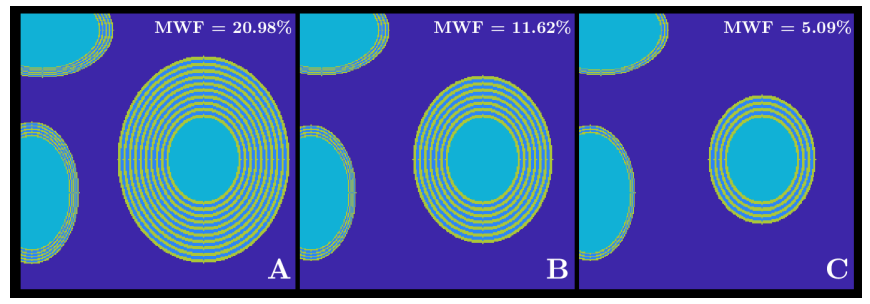

Fig. 1. Geometric voxel design utilized for multi-echo spin-echo Bloch simulations. Spins were equally distributed on a $256 \times 256$ grid over the $2 \mathrm{D}$ voxel. The MWF was varied between the three scenarios, yielding approximately $21 \%, 11.6 \%$ and $5.1 \%$ for A, B and C, respectively. These are subsequently referred to as Model 1, 2 and 3 (M1, $M 2, M 3)$, reflecting high to low myelin content. The colouring only distinguishes the four different tissue compartments and does not reflect different assigned relaxation times. Using this layout, tissue relaxation times were assigned to all spins by sampling from a Gaussian distribution around the mean compartmental relaxation time.

a 2D voxel (Figure 1). The layout was based on a publicly available electron microscopy image (https://upload.wikimedia.org/wikipedia/commons/c/c1/ Myelinated_neuron.jpg, accessed Sept 12th 2018). The voxel contained three myelinated axons, two of which had thinner myelin sheaths than the third, amounting to $21 \% \mathrm{MWF}$ (Fig. 1A). To assess whether lower MW contents can also be correctly estimated, the voxel layout was adjusted to yield approximately $11.6 \%$ and $5.1 \%$ MWF (Fig. 1B and C). These models are henceforth denoted as models (M) 1, 2, 3, corresponding to $21,11.6$ and $5.1 \%$ MWF.

We defined four subspaces: Extra-axonal water, intraaxonal water, water in between the myelin bilayers and the non-aqueous myelin bilayers. Literature $T_{2}$ and $T_{1}$ relaxation times [46-48] were assigned to spins in different compartments by random sampling from a Gaussian distribution around the mean compartmental $\mathrm{T}_{1}$ and $\mathrm{T}_{2}$. Local spin resonance frequencies were allocated by forward field computation of the magnetic susceptibility distribution [49] ( $\chi=0$ ppm for all water, $\chi=-0.02 \mathrm{ppm}$ for the myelin lipid bilayers, assuming $80 \%$ myelin lipids and $20 \%$ proteins [50,51]). Resonance frequency offsets (f) [52-54], relative to the extra-axonal water frequency, were then assigned to the different water pools considering the computed field perturbations. Intra- and extracellular water were assumed to have the same $\mathrm{T}_{1}$ and $\mathrm{T}_{2}\left(\mathrm{~T}_{1}=1200 \pm 200 \mathrm{~ms}\right.$ $\left.[47,48], \mathrm{T}_{2}=70 \pm 10 \mathrm{~ms}[46]\right)$, but different $\mathrm{f}$ (-3.052 and 0.053 $\mathrm{Hz}$, respectively). MW was presumed to exhibit a rapid signal decay in both $\mathrm{T}_{1}$ and $\mathrm{T}_{2}\left(\mathrm{~T}_{1}=600 \pm 100 \mathrm{~ms}[47,48], \mathrm{T}_{2}\right.$ $=$ varied from $3-20 \pm 5 \mathrm{~ms}[46], \mathrm{f}=7 \mathrm{~Hz}$ [53,54]). Very short, ("MR invisible") relaxation rates and high offset frequencies were modelled for the highly anisotropic non-aqueous myelin bilayers $\left(\mathrm{T}_{1}=120 \pm 20 \mathrm{~ms}, \mathrm{~T}_{2}=0.1 \pm 0.05 \mathrm{~ms}, \mathrm{f}=\right.$ $-20 \mathrm{~Hz}$ ). Note that the proton signal from myelin phospholipid bilayers does not decay exponentially, but is characterized by a Super-Lorentzian line shape $[55,56]$. Literature on $\mathrm{T}_{1}$ of the aqueous and non-aqueous parts of myelin is scarce and in vivo measurements are known to be affected by magnetization exchange [57]. Hence, $\mathrm{T}_{1}$ values represent approximate values only.

A linear frequency variation was added to the frequency map as encoding gradients impose much larger frequency offsets than induced locally [7]. Gaussian noise was added to the $T_{1}$ and $T_{2}$ maps and independently to the real and imaginary components of the complex field map (signal-tonoise ratio $(\mathrm{SNR})=250)$. 
Multi-echo spin-echo data were generated analogous to the in vivo MR protocol of the gradient-echo and spin-echo acquisition currently performed for MWI at $3 \mathrm{~T}$ [58]: 32 echoes, $\mathrm{TE} 1 / \Delta \mathrm{TE}=10 / 10 \mathrm{~ms}$ and $\mathrm{TR}=1200 \mathrm{~ms}$. The magnetization vector evolution was described with rotation matrices for each isochromat, allowing for spin excitation and dephasing in the rotating frame of reference. The Carr-Purcell-Meiboom-Gill spin-echo experiments consisted of a $90^{\circ}$ excitation pulse along $\hat{y}$ and subsequent $180^{\circ}$ refocusing pulses along, with the time between the excitation and first refocusing pulse being $\mathrm{TE}_{1} / 2$. At time of echo formation, the total magnetization of the set of isochromats was computed and the magnitude of the complex signal, i.e. the transverse component of the magnetization vector, was taken. For each of the three models (Fig. 1), we varied the MW $\mathrm{T}_{2}$ through $3,5,8,10,13,15,18$ and $20 \mathrm{~ms}$. Six refocusing FAs between $130^{\circ}-180^{\circ}$ were considered and the effect of shorter echo spacing was tested by also computing decay curves of 48 echoes at $8 \mathrm{~ms} \mathrm{TE} / \Delta \mathrm{TE}$ and 64 echoes at $6 \mathrm{~ms} \mathrm{TE} / \Delta \mathrm{TE}[59]$. Note that the 48 and 64 echo acquisitions included a few later TE times than the 32 echo acquisition. To accommodate the longer readouts, TR was chosen longer than typically used at $3 \mathrm{~T}$ for 32 echoes.

\section{Computation of $\mathbf{T}_{2}$ distributions and analysis parameters of} interest. The most fundamental step in correctly estimating $\mathrm{T}_{2}$ and subsequently the MWF from multi-echo MRI is the determination of the actual refocusing FA to account for the presence of stimulated echoes [45]. To this end, hypothetical $\mathrm{T}_{2}$ decay curves are computed by EPG for a number of $\mathrm{T}_{2}$ times $\left(\mathrm{T}_{2, i}\right)$ and at a few different FAs, typically eight, equally spaced between $100^{\circ}-180^{\circ}$. EPG identifies three magnetization phase configurations and traces state transitions by relaxation and transition matrices. The states, $\mathrm{F}_{n}, \mathrm{~F}_{n}^{*}$ and $\mathrm{Z}_{n}$, represent transverse and longitudinal dephasing and rephasing spins. Following the application of a radiofrequency pulse $\alpha$ with an initial phase of zero, state transitions occur by [45]

$$
\left(\begin{array}{c}
F_{n} \\
F_{n}^{*} \\
Z_{n}
\end{array}\right)^{\prime}=\left(\begin{array}{ccc}
\cos ^{2}(\alpha / 2) & \sin ^{2}(\alpha / 2) & -i \sin (\alpha) \\
\sin ^{2}(\alpha / 2) & \cos ^{2}(\alpha / 2) & i \sin (\alpha) \\
-\frac{1}{2} i \sin (\alpha) & \frac{1}{2} i \sin (\alpha) & \cos (\alpha)
\end{array}\right)\left(\begin{array}{c}
F_{n} \\
F_{n}^{*} \\
Z_{n}
\end{array}\right) \quad[1]
$$

Between refocusing pulses, spins may transition from $\mathrm{F}_{n}$ to $\mathrm{F}_{n}^{*}$ and reversely, noting that the sum of the magnetization in all states has to remain constant. Echoes are formed when $\mathrm{F}_{1}^{*}$ transitions to $\mathrm{F}_{1}$, with echo amplitudes corresponding to the magnitude of $\mathrm{F}_{1}^{*}$. When periodicity conditions are met, i.e. $\mathrm{TE}_{n}=\mathrm{n} \cdot \Delta \mathrm{TE}$, the number of configurations that need to be computed grows linearly with the number of echoes. If echoes with different phases occur, additional states need to be traced. An average, single exponential tissue $T_{1}(1 \mathrm{~s}$ for $\mathrm{WM}$ at $3 \mathrm{~T}$ [9]) and sequence parameters are also considered by EPG, including echo train length (ETL), $\Delta$ TE and the attempted refocusing pulse angle, customarily $180^{\circ}$ for spin-echo sequences. Note that computing voxel specific $\mathrm{T}_{1}$ times does not improve MWF estimation [45]. For each FA, NNLS determines the corresponding $\mathrm{T}_{2}$ distribution. $\mathrm{A}_{2}$ decay curve is then computed by back projection from the $\mathrm{T}_{2}$ distribution and compared to the measured data. The sum of squares of the residuals, i.e. $\chi^{2}$, is calculated for each FA.

$$
\chi^{2}=\sum_{\mathrm{TE}_{1}}^{\mathrm{TE}_{N}}\left(\text { decay }_{E P G}-\text { decay }_{\text {measured }}\right)^{2} .
$$

By cubic spline interpolation of all eight $\chi^{2}$, the FA corresponding to the minimum $\chi^{2}$, i.e. the actual FA, is established.

With the determined FA, EPG is used to recompute $T_{2}$ decay curves for each $\mathrm{T}_{2 i}$ time in the grid. The magnetization computed at each echo will depend on the echo amplitudes computed by EPG, the assumed proton density (PD), the longitudinal magnetization M0 and the excitation FA [45].

$\left(\begin{array}{c}M_{1} \\ M_{2} \\ \vdots \\ M_{\mathrm{ETL}}\end{array}\right)=M_{0} \cdot \sin \left(\alpha_{\text {excit }}\right) \cdot \mathrm{PD} \cdot \mathrm{EPG}\left(\mathrm{ETL}, \mathrm{TE}, T_{1}, T_{2}, A \cdot \alpha_{\text {prescribed }}\right)$

A represents the already computed deviation from the prescribed FA in each voxel. NNLS subsequently estimates the $\mathrm{T}_{2}$ distribution by comparing the theoretical decay curves to the measured data. The data remains unaltered when using EPG. Only the generated decay curves are adjusted to reflect imperfect signal refocusing and $T_{1}$ effects in the $T_{2}$ decay, thereby matching better to the acquired data. Due to discretization, resulting $\mathrm{T}_{2}$ distributions feature only delta-peaks at few $\mathrm{T}_{2}$ times, which may vary for different noise realizations. The sum $\mathrm{S}\left(\mathrm{T}_{2}\right)$ of the delta-functions for a given $\mathrm{T}_{2}$ with amplitudes ai determined at times $\mathrm{T}_{2 i}$ can be expressed as:

$$
S\left(T_{2}\right)=\sum_{i=1}^{n T_{2}} a_{i} \delta\left(T_{2}-T_{2 i}\right) \quad, \quad a_{i} \geq 0
$$

The amplitudes ai are larger or equal zero as $\mathrm{T}_{2 i}$ times are either present with a given amplitude or absent from the $\mathrm{T}_{2}$ distribution. This constraint turns Eq.4 into a non-linear problem. For the solution to resemble the true $\mathrm{T}_{2}$ distribution, the $\mathrm{T}_{2}$ grid needs to contain a sufficient number and range of $\mathrm{T}_{2 i}$ [16]. The $\mathrm{T}_{2}$ grid is established by logarithmic spacing between the lowest $\left(\mathrm{T}_{2, \min }\right)$ and highest $\mathrm{T}_{2}$, based on the number of allowed $\mathrm{T}_{2}$ times $\left(\mathrm{nT}_{2}\right)$ and the expected width of the $\mathrm{T}_{2}$ distribution. More $\mathrm{nT}_{2}$ times may enhance confidence in the determination of the different components in the $\mathrm{T}_{2}$ distribution, but will prolong processing time. Most researchers utilize $40 \mathrm{nT}_{2}$ times, encompassing $\mathrm{T}_{2}$ times between $15 \mathrm{~ms}$ and $2 \mathrm{~s}[46,60,61]$. At these parameters, $30 \mathrm{~min}$ to several hours are required to compute a whole brain MWF map, depending on available hardware. We tested NNLS with $\mathrm{nT}_{2}$ of 20,40 , 80 and $120 \mathrm{~T}_{2}$ times, while varying the lower bound of the $\mathrm{T}_{2}$ grid, $\mathrm{T}_{2, \text { min }}$, between $3-15 \mathrm{~ms}$ in $1 \mathrm{~ms}$ intervals.

$$
\text { Assuming that } y(\mathrm{TE})=\sum_{i=1}^{n T_{2}} a_{i} e^{-\mathrm{TE} / T_{2 i}} \text {, the signal } \mathrm{S}_{j} \text { of }
$$
echo $\mathrm{j}$ is defined by a system of linear equations

$$
S c_{j}=\sum_{i=1}^{n T_{2}} A_{j i} a_{i}
$$

The matrix coefficients $\mathrm{A}_{j i}$ represent the exponentials, or the decay signal computed by EPG. In principle, the amplitudes ai can be calculated by taking the pseudo-inverse of $\mathrm{A}_{j i}$. However, exact inverse solutions are contaminated by noisy data and no constraints, such as non-negativity of all ai, can be imposed. By contrast, NNLS allows for a misfit between the simulated and measured decay data yj, for instance due to noise, using the $\chi^{2}$ statistic (Eq.2). When minimizing 


$$
\sum_{j=\mathrm{TE}_{1}}^{\mathrm{TE}_{N}}\left|\sum_{i=1}^{n T_{2}} A_{j i} a_{i}-y_{j}\right|^{2} .
$$

all ai are implicitly constrained to be non-negative by NNLS operating as an active set algorithm. The active set contains the regression coefficients, i.e. signal amplitudes, that are negative or zero when estimated without constraints. If the true active set were known, the solution would equal the unconstrained solution of all non-negative coefficients [62]. Starting with a zero vector where all coefficients are nonnegative, NNLS approaches a prediction of the active set by iterative combination of all $\mathrm{T}_{2, i}$ with different amplitudes, fulfilling the non-negativity constraint.

Regularization is employed to produce continuous distributions of $\mathrm{T}_{2}$ relaxation times, which are expected to conform to reality. Thereby, adjacent peaks are merged to form a few distinct water pools. To constrain $\mathrm{T}_{2}$ distributions, an 12-norm regularization term is incorporated into Eq.6,

$$
\sum_{j=\mathrm{TE}_{1}}^{\mathrm{TE}_{N}}\left|\sum_{i=1}^{n T_{2}} A_{j i} a_{i}-y_{j}\right|^{2}+\mu \sum_{i=1}^{n T_{2}} a_{i}^{2}
$$

which minimizes the system's "energy" to produce smooth, continuous $\mathrm{T}_{2}$ distributions [42]. By increasing the strength of the regularization, the central IEW peak becomes broader, while the short fraction size reduces. Other regularization, e.g. by the first or second order derivatives of the spectrum, may also be used $[16,63]$.

Without regularization, $\chi_{\min }^{2}$ reflects the misfit in each data point by about one standard deviation [16]. With regularization, $\chi_{\min }^{2}$ will be adjusted incrementally to increase $\chi^{2}$, since it is typically too low, fitting data too accurately $[16,42]$. The ratio of $\chi^{2}$ over $\chi_{\text {min }}^{2}$ has commonly been set to 1.02 [60]. The misfit depends on the acquisition type and noise level.

To test the robustness of NNLS with respect to noise and the influence of regularization, both the decay curve SNR and the $\chi^{2} / \chi_{\min }^{2}$ ratio were varied. White Gaussian noise was independently added to each of the computed decay curves (Matlab's awgn function). Thereby, the power of the input signal was assessed before noise was added, yielding prescribed decay curve SNR levels of 30, 50, 100, 150, 200, 250, 300, 500 and 1000. The noisy data was in some cases compared to decay curves without added noise, i.e. no specific SNR level was generated. The regularization parameter was varied to yield $\chi^{2} / \chi_{\min }^{2}$ of $1.02,1.05,1.1,1.15,1.25$, i.e. allowing misfits of $2-25 \%$.

The estimated geometric mean $(\mathrm{gm}) \mathrm{T}_{2}$ of the IEW and MW peak and the obtained MWF were compared to the ground truth to assess the accuracy of the NNLS solutions with EPG.

In vivo data. To relate the simulations to in vivo imaging, MWI data from one female healthy volunteer (age 23 years) was collected. The volunteer gave written informed consent. One 32 echo GraSE $\mathrm{T}_{2}$ data set was acquired at a $3 \mathrm{~T}$ Philips Achieva (Best, The Netherlands) with an eight-channel head coil, using $\mathrm{TE} / \Delta \mathrm{TE} / \mathrm{TR}=10 / 10 / 1000 \mathrm{~ms}$ [57]. The data were processed with the regularized NNLS, as described for the simulated data, using $\mathrm{T}_{2, \min }=15 \mathrm{~ms}, \mathrm{nT}_{2}=40$ and $\chi^{2} / \chi_{\min }^{2}$ $=1.02$, typical for in vivo multi-component $\mathrm{T}_{2}$ analysis $[57,58]$.

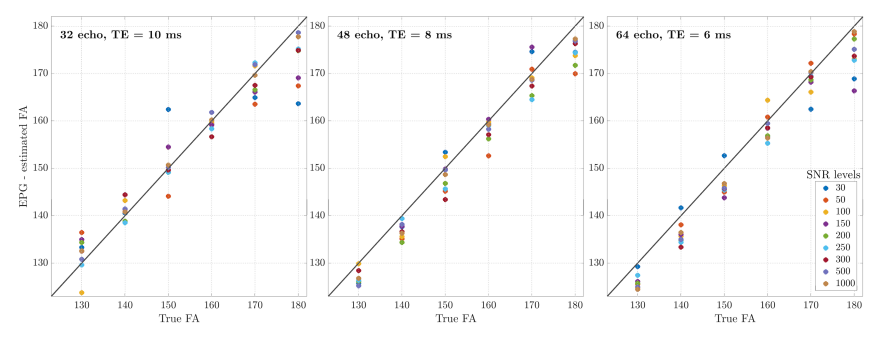

Fig. 2. EPG-FA estimation in the presence of stimulated echoes and at different noise levels in the highest myelin water model (MWF $=21 \%$ ). Independent of the acquisition type and for most SNR levels, EPG estimated FAs were within a few degrees of the true FA value, indicated by the black line. At very low SNR levels, deviations between the true and estimated FA were noticeable, but lower and higher FAs could still be well distinguished.

\section{Results}

Extended Phase Graph - Flip Angle estimation. The reliability of the FA estimation by EPG depends predominantly on SNR. Figure 2 compares the FA estimates for the different acquisition types and decay curve noise levels. Despite greater variation from the true FA at lower SNR, estimated and true FAs still correlated linearly at all SNR levels $(\mathrm{p}<0.023, \mathrm{r}>0.873)$. In the 32 -echo simulation, the average slope was $0.836 \pm 0.140$ for all SNR levels. For 48-echoes and 64-echoes, FA estimates improved and the average slopes of the regression lines were $0.996 \pm 0.060$ and $1.022 \pm 0.066$, respectively. Note that EPG estimates $\mathrm{B}^{+}{ }^{+}$inhomogeneities relative to the assumed refocusing angle of $180^{\circ}$, so that larger FAs, e.g. $190^{\circ}$, are displayed as $170^{\circ}$.

Table 1 summarizes the SNR-dependent root-mean squared error (RMSE) of the FA estimates across different acquisition types and the three MWF models (M1, M2, M3). The three acquisition types are referred to by their ETL: $32 \mathrm{e}, 48 \mathrm{e}$ and $64 \mathrm{e}$ indicating acquisitions of 32 echoes with $10 \mathrm{~ms} \Delta \mathrm{TE} ; 48$ echoes with $8 \mathrm{~ms} \Delta \mathrm{TE}$ and 64 echoes with $6 \mathrm{~ms} \Delta \mathrm{TE}$, respectively. With improving decay curve SNR, FA estimates became more reliable. Similar RMSE estimates indicated little difference between acquisitions using different $\Delta \mathrm{TE}$. Across all noise levels, models and acquisition types, the estimated FAs were $127.8 \pm 3.6^{\circ}, 138.4 \pm 3.7^{\circ}, 148.6 \pm 3.9^{\circ}, 158.9 \pm 3.2^{\circ}, 168.5 \pm$ $3.1^{\circ}, 173.5 \pm 4.2^{\circ}$ relative to the true FAs of $130^{\circ}, 140^{\circ}, 150^{\circ}$, $160^{\circ}, 170^{\circ}$ and $180^{\circ}$. The apparent difficulty in capturing FA $=180^{\circ}$ (see also Fig. 2) is due to the FA limit of $180^{\circ}$ with EPG. Small systematic deviations from $180^{\circ}$, however, are of little consequence for the EPG signal decay.

Given that only a limited number of $\mathrm{T}_{2 i}$ times is used to describe the $\mathrm{T}_{2}$ decay, some variance is expected with respect to $\mathrm{nT}_{2}$ and the choice of $\mathrm{T}_{2, \text { min }}$. For a particular acquisition type and model $\left(\mathrm{M} 2,48 \mathrm{e}, \mathrm{MW} \mathrm{T}_{2}=10 \mathrm{~ms}\right.$, SNR $=500)$, changing $\mathrm{nT}_{2}$ yielded on average variations of less than $1^{\circ}$ across all FAs. Changing the $\mathrm{MW} \mathrm{T}_{2}$ led to arbitrary, nonsystematic variations in the FA estimation. On the other hand, changing $\mathrm{T}_{2, \text { min }}$ from the lowest to highest ( $3 \mathrm{~ms}$ to 15 ms) resulted in variations of $1^{\circ}-4^{\circ}$ from the true FA with a tendency towards higher FAs for longer $\mathrm{T}_{2, \text { min }}$. Regularization played no role in the FA estimation.

Decay curve SNR and $\mathrm{B1}^{+}$inhomogeneities: Comparison of simulated and in vivo data. The SNR of the decay curves affects the FA estimation, with low SNR also resulting in 
bioRxiv preprint doi: https://doi.org/10.1101/2020.02.15.948976; this version posted February 17, 2020. The copyright holder for this preprint (which was not certified by peer review) is the author/funder, who has granted bioRxiv a license to display the preprint in perpetuity. It is made available under aCC-BY-NC-ND 4.0 International license.

Table 1. Summary of the RMSE estimates between true and estimated rFAs. RMSE are given in units of [ ${ }^{\circ}$ FA]. M1, M2, M3 indicate the three models of different MWFs, going from highest in M1 (21\%) to lowest in M3 (5.1\%).

\begin{tabular}{|c|c|c|c|c|c|c|c|c|c|}
\hline Sequence SNR & 30 & 50 & 100 & 150 & 200 & 250 & 300 & 500 & 1000 \\
\hline M1 - 32e & 8.74 & 6.82 & 4.02 & 5.77 & 3.24 & 2.38 & 3.40 & 1.39 & 1.48 \\
\hline M1 - 48e & 3.81 & 6.03 & 3.30 & 3.39 & 5.18 & 3.98 & 3.79 & 2.61 & 2.42 \\
\hline M1 - 64e & 5.80 & 3.07 & 4.87 & 6.59 & 3.73 & 4.71 & 4.74 & 3.91 & 3.35 \\
\hline M2 - 32e & 8.44 & 8.26 & 4.58 & 6.13 & 3.11 & 2.13 & 2.72 & 3.11 & 2.12 \\
\hline$M 2-48 e$ & 7.13 & 5.01 & 4.75 & 5.46 & 4.09 & 2.48 & 2.90 & 3.12 & 2.90 \\
\hline M2 - 64e & 4.83 & 5.04 & 5.18 & 5.75 & 4.21 & 4.48 & 2.66 & 4.19 & 3.04 \\
\hline M3 - 32e & 8.09 & 10.19 & 4.83 & 3.86 & 4.24 & 2.25 & 3.32 & 2.30 & 2.39 \\
\hline$M 3-48 e$ & 5.97 & 6.21 & 5.59 & 3.84 & 5.69 & 2.30 & 4.28 & 2.14 & 1.68 \\
\hline M3 - 64e & 7.34 & 5.52 & 4.17 & 7.66 & 2.62 & 4.94 & 3.63 & 4.02 & 2.65 \\
\hline
\end{tabular}

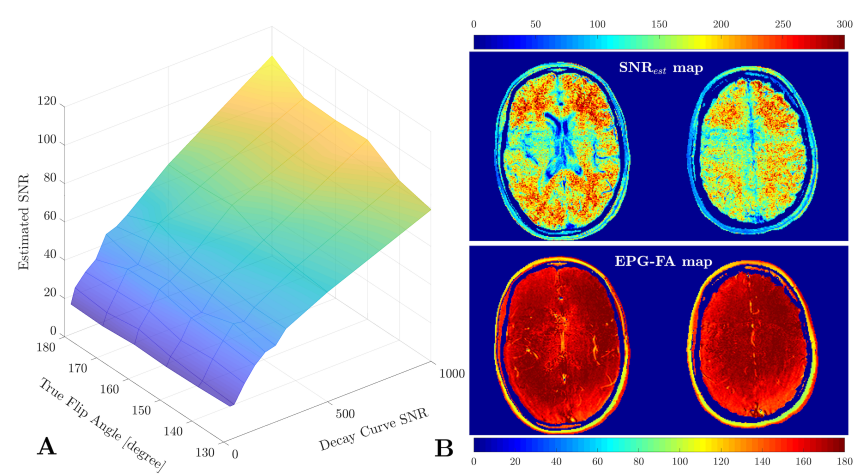

Fig. 3. A) Estimated SNR, given the maximum signal of the decay curve and the residuals, relative to the true FA and SNR that was assigned to the decay. As expected, larger initial SNRs and larger FAs yielded larger SNR s. $_{\text {. }}$. (B) In vivo SNRest and EPGFA map are displayed for two different brain slices. SNRest is indirectly dominated by the local FA via the steady-state + receive sensitivity of the 8-channel head coil. A direct spatial correlation with the EPG-FA maps, however, cannot be seen. SNRest values clearly distinguished white and gray matter regions, with WM SNRest being > 180.

significant residuals. Importantly, while lower FAs produce systematically lower signal at the first echo by inefficient refocusing, a signal increase due to positive noise at the first echo could lead to an overestimation of the MWF. Together $\mathrm{B}^{+}$inhomogeneity and the decay curve SNR contribute to the estimated SNR (SNRest) that is obtained from the NNLS fit.

$$
\mathrm{SNR}_{\text {est }}=\frac{\max \left(\text { decay }_{\text {signal }}\right)}{\sqrt{\operatorname{var}(\text { residuals })_{1}}} .
$$

The surface plot in Figure 3A exemplifies the influence of these two parameters on SNRest for M2, 32e. In vivo data acquired at $3 \mathrm{~T}$ are depicted for comparison in panel $\mathrm{B}$.

In vivo data yielded SNRest values $>180$ and FAs of $>$ 150 for most WM. By comparison, SNRest of the simulation at FAs around $180^{\circ}$ and signal $\mathrm{SNR}=1000$ was just over 100. Thus, particularly in WM, the decay curve SNR at respective FAs in vivo appears to be sufficient for $\mathrm{T}_{2}$ estimation, and the simulated data represent possibly worse signal SNR scenarios than encountered in vivo at $3 \mathrm{~T}$. This is further supported by the direct comparison of the decay curves (Figure 4). At comparable FAs, the decay curves displayed similar stimulated echo and noise patterns for high SNR values. Thus, all subsequent figures and computations will evaluate the decay
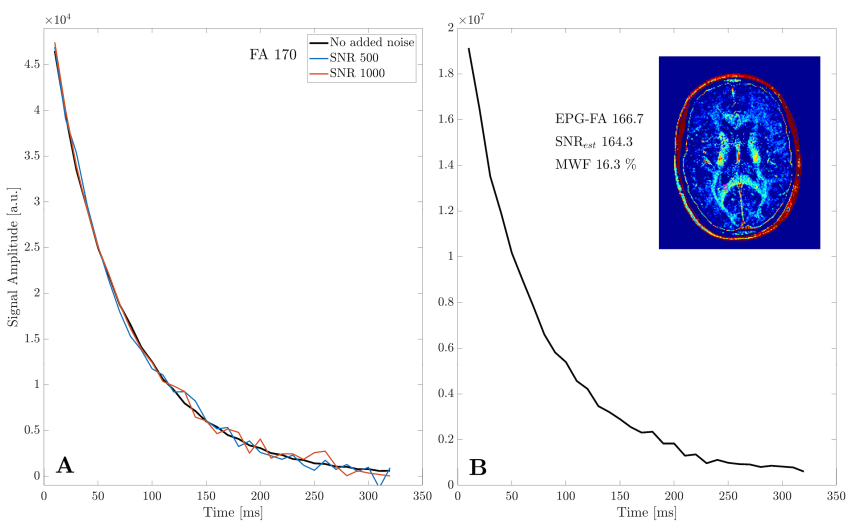

Fig. 4. Direct comparison of simulated $(A)$ and experimental $(B)$ decay curves for a typical WM voxel, here of the splenium of the corpus callosum, yielding FA and MWF estimates in line with the simulation (M2, 32e, FA $\left.170^{\circ}\right)$. Note that 'no added noise' means no white Gaussian noise was added to the decay curve, but Gaussian noise was present in the $T_{1}$ and $T_{2}$ distributions of the simulated image voxel.

curves with a simulated decay curve $\mathrm{SNR}=1000$.

Relationship between $\mathbf{T}_{2, \min }$ and $\mathbf{M W} \mathbf{T}_{2}$ time. To understand the relationship between the choice of $\mathrm{T}_{2, \min }$ and the $\mathrm{MW}$ $\mathrm{T}_{2}$ time, it is most informative to look at the regularized $\mathrm{T}_{2}$ distributions (Figure 5). Independent of $\mathrm{T}_{2, \min }, \mathrm{FA}$, noise level or $\mathrm{MW} \mathrm{T}_{2}$, the IEW peak was centered at the true IEW $\mathrm{T}_{2}$ time. Nonetheless, the $\mathrm{gmT}_{2}$ deviated slightly from the true value (IEW gmT $\mathrm{gme}_{2}$ time: panel A $66.4-67.5 \mathrm{~ms}$, B 69.3 $-70.2 \mathrm{~ms}$, C $71.0-71.4 \mathrm{~ms}$ ), likely introduced by the limited data sampling of the $\mathrm{T}_{2}$ distributions. For instance, with $\mathrm{nT}_{2}=40,4-7$ data points characterized the IEW peak. Choosing larger $\mathrm{nT}{ }_{2}$ may provide more stable estimates of the IEW $\mathrm{gmT}_{2}$. But, the gain in better estimating the IEW $\mathrm{gmT}_{2}$, relative to the choice of $\mathrm{nT}_{2}$, is small (about $1 \mathrm{~ms}$ ) and computational time must be weighed against minimally improved accuracy.

Due to its rapid decay and lesser signal, the MW compartment is more sensitive to noise than the IEW component. Hence, the MW pool was typically represented by only one or two elevated points rising towards $\mathrm{T}_{2, \text { min }}$, rather than a peak (panels $\mathrm{A}-\mathrm{D}$ ), indicating that our acquisitions and $\mathrm{T}_{2}$ distributions have insufficient range to fully describe the MW signal. On the contrary, $\mathrm{T}_{2}$ distributions representing decay curves with no added Gaussian noise (E \& F), explicitly captured the influence of $\mathrm{T}_{2, \min }$ on the MW peak. In panel $\mathrm{F}$, when $\mathrm{T}_{2, \min }$ 


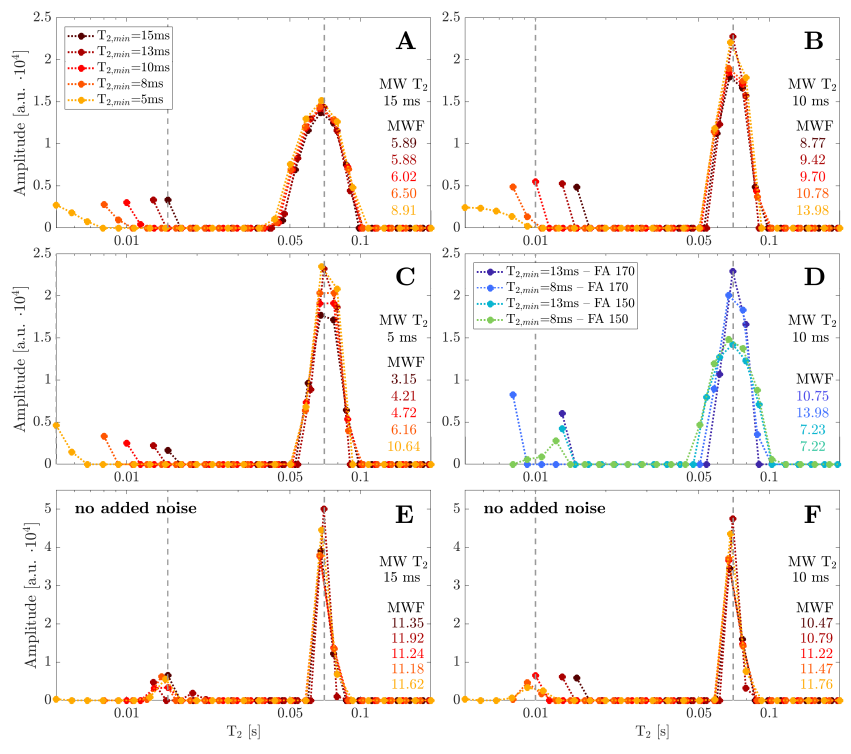

Fig. 5. Comparison of $\mathrm{T}_{2}$ distributions obtained by regularized NNLS with varying $\mathrm{T}_{2, \text { min }}$, noise levels and FAs. Data shown here correspond to M2, i.e. $11.6 \% \mathrm{MWF}$, $48 \mathrm{e}$ and $\mathrm{nT}_{2}=40$. Panels $\mathrm{A}-\mathrm{D}$ correspond to decay curves with $\mathrm{SNR}=1000$ compared to $E$ and $F$, where no additional noise was applied to the decay curves. All red-color scheme curves $\left(A-C, E\right.$ \& $F$ ) correspond to $F A=180^{\circ}$ and $D$ shows examples of lower FAs. Vertical dashed lines indicate the true $M W T_{2}$ and IEW $T_{2}$ times. The $5 \mathrm{~ms} \mathrm{MW} \mathrm{T}_{2}$ line in panel $\mathrm{C}$ is co-localized with the $\mathrm{y}$-axis. IEW $\mathrm{T}_{2}$ was $70 \mathrm{~ms}$ in all simulations. The $\mathrm{MW} \mathrm{T}_{2}$ times are listed on the right side of each plot. The MWF estimate for each $\mathrm{T}_{2, \min }$ is quoted in the lower right hand corner of each panel.

$>\mathrm{MW} \mathrm{T}_{2}$, the MW "peak" was a slope, characterized by a single $\mathrm{T}_{2 i}$ time, pushing towards the lowest allowed $\mathrm{T}_{2}$, i.e. $\mathrm{T}_{2, \text { min }}$. Once $\mathrm{T}_{2, \text { min }}<\mathrm{MW} \mathrm{T}_{2}$, small peaks formed that fully depicted the short $\mathrm{T}_{2}$ signal and the $\mathrm{MW} \mathrm{gmT}_{2}$ resembled the true $\mathrm{MW} \mathrm{T}_{2}$. For $\mathrm{MW} \mathrm{T}_{2}=10 \mathrm{~ms}$ (panel $\mathrm{F}$ ), the estimated MW $\mathrm{gmT}_{2}$ was $15,13,10,9.5,9.4 \mathrm{~ms}$ for $\mathrm{T}_{2, \min }$ of 15,13 , 10,8 and $5 \mathrm{~ms}$. In the presence of added noise (panels $\mathrm{A}-$ $\mathrm{D})$, both $\mathrm{T}_{2}$ peaks became wider, which made it particularly difficult to capture the short $\mathrm{T}_{2}$ component fully.

It needs to be determined how strongly the MWF assessment depends on the selection of $\mathrm{T}_{2, \min }$ and the estimation of the MW $\mathrm{gmT}_{2}$. Furthermore, it needs to be ascertained how short $\mathrm{T}_{2, \min }$ can be selected relative to the shortest acquisition TE (e.g. 6, 8 or $10 \mathrm{~ms}$ ) to recover the true MWF.

Estimating the geometric mean $\mathrm{T}_{2}$ of the intermediate water - IEW - compartment In healthy WM, the intermediate $\mathrm{T}_{2}$ is assigned to water in the axonal lumen, cell bodies and interstitium. The IEW peak is relatively broad, with a $\mathrm{gmT}_{2}$ of approximately $68-72 \mathrm{~ms}$ at $3 \mathrm{~T}$ [59]. Therefore, varying $\mathrm{nT}_{2}$ hardly influenced the determination of IEW $\mathrm{gmT}_{2}$ (variations approximately $1 \mathrm{~ms}$ ). Increasing regularization progressively reduced the IEW $\mathrm{gmT}_{2}$ from the true time of $70 \mathrm{~ms}$. Lower FAs did not systematically underestimate IEW $\mathrm{gmT}_{2}$. Differences in $\mathrm{T}_{2, \min }$ changed IEW $\mathrm{gmT}_{2}$ by less than $3 \mathrm{~ms}$. When the IEW $\mathrm{gmT}_{2}$ was not stable with respect to $\mathrm{T}_{2, \text { min }}$, it approached the true value when the $T_{2, \min }$ was closer to the $\mathrm{MW} \mathrm{T}_{2}$ (Supplementary Table 1 ). If $\mathrm{T}_{2, \min }$ was longer than the MW $\mathrm{T}_{2}$, IEW $\mathrm{gmT}_{2}$ increased above the true value, in line with the observations from Fig. 5C. In turn, for long MW $\mathrm{T}_{2}$ (20 ms, Fig.5A), the IEW gmT 2 was underestimated. The amount of MW did not affect the IEW gmT 2 estimation.
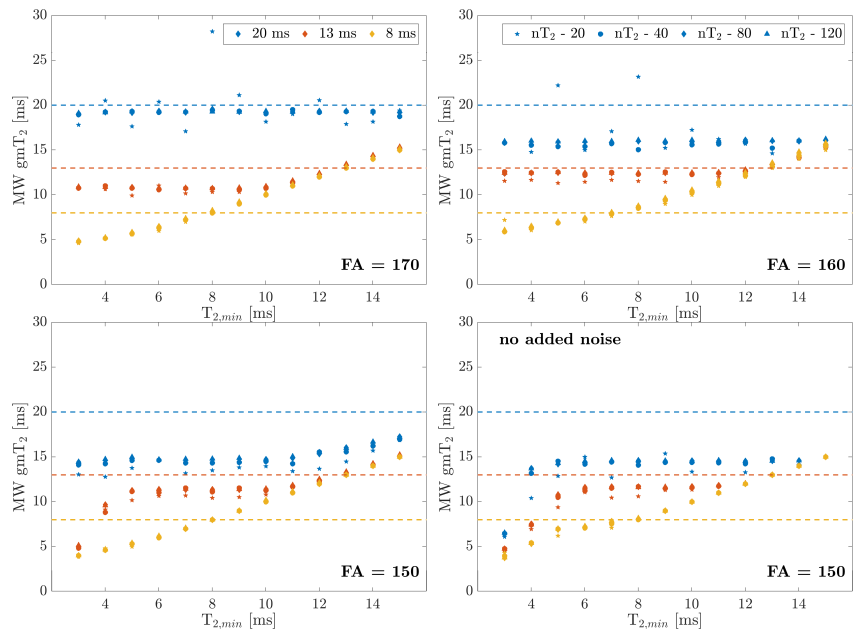

Fig. 6. $\mathrm{MW} \mathrm{gmT}_{2}$ estimates for various $\mathrm{FAs}, \mathrm{T}_{2, \text { min }}, \mathrm{nT}_{2} \mathrm{~s}$ and true $\mathrm{MW} \mathrm{T}_{2}$ times. Typically, MW $\mathrm{gmT}_{2}$ estimates yielded stable solutions if $\mathrm{T}_{2, \text { min }} \pm \mathrm{MW} \mathrm{T}_{2}$, however, the stable solution may estimate $\mathrm{gmT}_{2}$ to be shorter than the true $\mathrm{MW} \mathrm{T}_{2}$. Here, the SNR was 1000 for all panels except the bottom right panel.

Across all FAs, $\mathrm{T}_{2, \min }$ and $\mathrm{MW} \mathrm{T}_{2}$ times, we obtained $66.2 \pm$ $2.2 \mathrm{~ms}, 66.7 \pm 2.1 \mathrm{~ms}$ and $66.4 \pm 2.2 \mathrm{~ms}$ for M1 $(32 / 48 / 64 \mathrm{e}$, respectively), $66.7 \pm 1.6 \mathrm{~ms}, 66.8 \pm 1.6 \mathrm{~ms}$ and $66.8 \pm 1.6$ $\mathrm{ms}$ for $\mathrm{M} 2$, and $67.6 \pm 1.5 \mathrm{~ms}, 67.7 \pm 1.6$ and $67.6 \pm 1.5 \mathrm{~ms}$ for M3, yielding an approximate variation of $3-4 \mathrm{~ms}$ from the true value $\left(c h i^{2} / \chi_{\min }^{2}=1.02\right)$. Without the addition of noise to the decay data, IEW $\mathrm{gmT}_{2}$ times were closer to the ground truth (less than $2 \mathrm{~ms}$ difference) and demonstrated a dependency on FA. For M1, 32e the obtained IEW $\mathrm{gmT}_{2}$ was $69.5 \pm 0.8 \mathrm{~ms}$ at $180^{\circ}, 69.2 \pm 0.9 \mathrm{~ms}$ at $170^{\circ}, 68.4 \pm 1.4 \mathrm{~ms}$ at $150^{\circ}$ and $68.4 \pm 1.5 \mathrm{~ms}$ at $130^{\circ}$.

Estimating the geometric mean $\mathrm{T}_{2}$ of the MW peak and the MWF . When comparing the true and estimated $\mathrm{MW} \mathrm{gmT}_{2}$ at different FAs (M2 - 48e), the three MW T 2 's of 20, 13 and $8 \mathrm{~ms}$ were only accurately reproduced at relatively high FAs and $\mathrm{T}_{2, \min }<\mathrm{MW} \mathrm{T}_{2}$. Once $\mathrm{T}_{2, \min }<\mathrm{MW} \mathrm{T}_{2}$, the $\mathrm{MW}$ $\mathrm{gmT}_{2}$ reached a plateau and the solution remained stable in most cases (Figure 6). However, the plateau $\mathrm{gmT}_{2}$ time was typically shorter than the true $\mathrm{MW} \mathrm{T}_{2}$, particularly at lower FAs. If $\mathrm{TT}_{2, \min }$ was very short, $\mathrm{MW} \mathrm{gmT}_{2}$ tended to decline further. Moreover, it can be difficult to reach a stable solution, if $\mathrm{MW} \mathrm{T}_{2}$ is short, e.g. $\mathrm{MW} \mathrm{T}_{2}=8 \mathrm{~ms}$. In the absence of added noise (lower right panel) a similarly plateauing behavior was observed, with some plateau values closer to the true $\mathrm{T}_{2}$ time than in the SNR $=1000$ case. Again, the dependence on FA was less pronounced when noise was added to the decay curves. Without added noise, the median $\mathrm{MW} \mathrm{gmT}_{2}$ for the $20 \mathrm{~ms} \mathrm{MW} \mathrm{T}_{2}$ was $19.5,19.4,17.5$ and $14.6 \mathrm{~ms}$ at $180^{\circ}, 170^{\circ}$, $160^{\circ}, 150^{\circ}$. For $13 \mathrm{~ms} \mathrm{MW} \mathrm{T}_{2}$, we obtained 12.7, 12.9, 11.8 and $11.7 \mathrm{~ms}$ at the decreasing FAs and $9,9,9$ and $9 \mathrm{~ms}$ relative to the $8 \mathrm{~ms}$ true $\mathrm{MW} \mathrm{T}_{2}$ for the same M2, 48e acquisition.

Variations with $\mathrm{nT}_{2}$ were on average below $1 \mathrm{~ms}$, with $\mathrm{nT}_{2}=20 \mathrm{~T}_{2}$ times yielding the largest offsets from the other $\mathrm{nT}_{2}$ estimates. Larger $\mathrm{nT}_{2}$ tended to increase the $\mathrm{MW} \mathrm{gmT}_{2}$ minimally. Stronger regularization led in some cases to much longer $\mathrm{MW} \mathrm{gmT}_{2}$, presumably a result of coalescence of the two water peaks. Correspondingly, with increasing regularization, the MWF tended to decrease initially, and then increase as the 


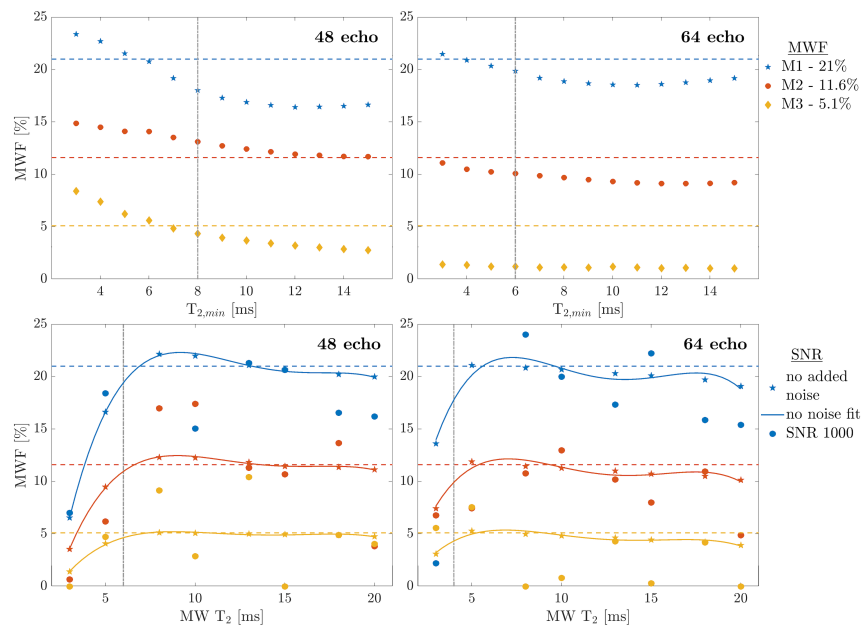

Fig. 7. Mean MWF estimates relative to the true values at different $T_{2, \text { min }}$ (top) and $M W T_{2}$ times (bottom), at SNR $=1000, \chi^{2}=1.02, \mathrm{nT}_{2}=120$. Top row: Mean MWF averaged over different $M W \mathrm{~T}_{2}$ times $(15,13,10$ and $8 \mathrm{~ms})$ for different acquisition strategies at $F A=170^{\circ}$. The true MWF values $(21,11.6$ and $5.1 \%)$ are shown for comparison as dashed lines. The gray, dash-dotted verticals indicate the acquisition $T E$, relative to $T_{2, \min }$. On average, MWF values are closest to the true value when $T_{2}, \min$ is chosen to be just below TE1. Bottom row: Mean MWF values for different $\mathrm{MW} \mathrm{T}_{2}$ times computed at a specified $\mathrm{T}_{2, \min }$ (gray, dash-dotted vertical line). Estimates are compared in the presence (filled circles) and absence of noise (filled stars). A fourth-order polynomial fit was applied to the no added noise data. Even in the absence of noise, the MWF is strongly underestimated if $\mathrm{MW} \mathrm{T}_{2}$ is shorter than $\mathrm{T}_{2, \text { min }}=\mathrm{TE}-2 \mathrm{~ms}$. For all $\mathrm{MW}_{2}$ that are longer than the selected $\mathrm{T}_{2}$, min time, the estimated MWF approaches the true value. At SNR 1000 (filled circles), estimated MWF vary more around the true value. Note that the $x$-axes differ; top row $\mathrm{T}_{2, \text { min }}$, bottom row $\mathrm{MW} \mathrm{T}_{2}$.

peaks merged and the consolidated peak extended into the MW $\mathrm{T}_{2}$ window. Table 2 compares the estimated $\mathrm{MW} \mathrm{gmT}_{2}$ time (left) in the three models and for the three different acquisition approaches relative to the selected $\mathrm{T}_{2, \min }$, and contrasts $\mathrm{gmT}_{2}$ estimates with the obtained MWF values (right).

$\mathrm{MW} \mathrm{gmT}_{2}$ estimates improved in many cases for acquisitions with shorter echo spacing. Particularly the $48 \mathrm{e}, 8 \mathrm{~ms}$ echo spacing acquisition showed stable estimates, close to the true MW $\mathrm{T}_{2}$ time of $20 \mathrm{~ms}$. Notably, even in the presence of unstable $\mathrm{MW} \mathrm{gmT}_{2}$ estimates, MWFs were consistent across $\mathrm{T}_{2, \text { min }}$, albeit underestimated for the $20 \mathrm{~ms} \mathrm{MW} \mathrm{T}_{2}$. Figure 7 summarizes the relationship between MWF, MW $\mathrm{T}_{2}$ and selection of $\mathrm{T}_{2, \text { min }}$. Data for $48 \mathrm{e}$ and $64 \mathrm{e}$ are shown; 32e data are provided in Supplementary Figure 1. The top row displays the mean behavior in estimated MWF across MW $\mathrm{T}_{2}$ times of $15,13,10$ and $8 \mathrm{~ms}$ relative to $\mathrm{T}_{2, \text { min }}$, since typically the true $\mathrm{T}_{2}$ time of the MW compartment is unknown. The bottom row illustrates at the relationship of MWF and individual MW $\mathrm{T}_{2}$ after selection of $\mathrm{T}_{2, \text { min }}$.

Average MWF estimates were relatively stable for $T_{2, \text { min }}$ $>$ TE1, although often underestimated (top row). In most cases, the estimated MWF was closest to the true value if $\mathrm{T}_{2, \text { min }}$ was just below or on the order of TE1. However, the exact relationship depended on the true $\mathrm{MW} \mathrm{T}_{2}$. Selecting $\mathrm{T}_{2, \min }$ according to TE1, i.e. $8 \mathrm{~ms}$ for $10 \mathrm{~ms} \mathrm{TE}, 6 \mathrm{~ms}$ for $8 \mathrm{~ms} \mathrm{TE}$, and $4 \mathrm{~ms}$ for $6 \mathrm{~ms} \mathrm{TE}$, we obtained $14.63 \pm 6.61 \%$, $17.66 \pm 5.57 \%$ and $17.79 \pm 7.28 \%$ for $32 \mathrm{e}, 48 \mathrm{e}$ and $64 \mathrm{e}$, across all possible MW $\mathrm{T}_{2}$ times (bottom row, filled circles). These estimates were lower than the true MWF of $21 \%$ due to the inclusion of $\mathrm{MW} \mathrm{T}_{2}$ times shorter than $\mathrm{T}_{2, \min }$. Excluding data for which MW $\mathrm{T}_{2}<\mathrm{T}_{2, \min }$, the average MWFs were 17.00 $\pm 5.82 \%, 19.31 \pm 4.17 \%$ and $20.01 \pm 3.95 \%$ for $32 \mathrm{e}, 48 \mathrm{e}$ and $64 \mathrm{e}$, respectively, for M1, $12.19 \pm 5.46 \%, 12.32 \pm 5.00 \%$ and $9.32 \pm 2.71 \%$ for M2 (true fraction $11.6 \%$ ) and $3.76 \pm 3.07 \%$, $5.23 \pm 3.92 \%$ and $2.45 \pm 2.94 \%$ for M3 (true fraction $5.1 \%$ ), at appropriately chosen $\mathrm{T}_{2, \text { min }}$. Shorter echo spacing improved the consistency of the MWF estimation across MW $\mathrm{T}_{2}$ times, as reflected in the smaller standard deviations. Regardless, MWFs differed insignificantly between acquisition schemes, if $\mathrm{T}_{2, \min }$ was chosen as described. Overall, the true MWF was underestimated by $0.13-4$ percentage points (at $170^{\circ}, \mathrm{SNR}=$ $1000, \chi^{2} / \chi_{\min }^{2}=1.02$ ). In the absence of added noise (filled stars and fitted line), MWF values demonstrated an even higher degree of similarity, deviating from the true value by $0.02-0.64$ percentage points. Specifically, we obtained 20.36 $\pm 0.31 \%$ for $32 \mathrm{e}, 21.02 \pm 0.90 \%$ for $48 \mathrm{e}$ and $20.26 \pm 0.69 \%$ for $64 \mathrm{e}$, close to the true value of $21 \%$ MWF. For M2, we found $11.230 \pm .24 \%, 11.73 \pm 0.49 \%$ and $11.00 \pm 0.60 \%$ and for M3 $4.620 \pm .17 \%, 4.970 \pm .14 \%$ and $4.62 \pm 0.46 \%$, respectively, for $32 \mathrm{e}, 48 \mathrm{e}$ and $64 \mathrm{e}$ at appropriately chosen $\mathrm{T}_{2, \text { min }}$.

\section{Discussion}

Importance of $\mathbf{B 1}^{+}$homogeneity and SNR. The EPG algorithm has much enhanced our ability to accurately interpret $\mathrm{T}_{2}$ decay data in the presence of stimulated echoes [45]. Yet, even when modeling spurious echoes in the $\mathrm{T}_{2}$ decay, imperfect refocusing pulses yield reduced signal amplitudes at early odd echoes, which leads to slight, systematic underestimations in $\mathrm{gmT}_{2}$ time and MWF. Notably, underestimations in MWF and IEW $\mathrm{gmT}_{2}$ also occur in the presence of noise44. Thus, while the influence of sub-optimal refocusing FAs and increased noise are clearly characterized individually, their combined presence leads to less systematic, and therefore less interpretable effects. Although noise affects predominately the residuals of the later echoes, noise in earlier data points may be mistakenly interpreted as stimulated echo artifact and vice versa.

Here, we used small-scale constraints, which increased $\chi^{2}$ to raise accuracy in the NNLS component estimation. Graham et al. showed that least squares-based constraints, as compared to $\chi^{2}$, may be advantageous at intermediate to low SNR in obtaining acceptable accuracy in determining multiple $\mathrm{T}_{2}$ components [42]. In early years of multi-echo $\mathrm{T}_{2}$ analysis, acquisition parameters of $\mathrm{TE}=10 \mathrm{~ms}, 32$ echoes and voxel SNR of 100, as determined at TE $=0 \mathrm{~ms}$ and the standard deviation of the noise, did not match the optimal TE of 6.4 ms and SNR of 700, then quoted to be required to resolve multiple $\mathrm{T}_{2}$ components by NNLS [42]. As shown in Figure 3 , these limits may now be regarded as too strict. With advancing MR hardware and newer acquisitions, we are coming closer to achieving optimal data collection, and traditional restrictions for multi-component $\mathrm{T}_{2}$ analyses may need to be revised. Nevertheless, regularization should be used conservatively, allowing data misfit of only a few percent, typically 1 or $2 \%$ [64] of that of the unregularized $\chi^{2}$, as stronger Tikhonov regularization quickly affects both MWF and IEW $\mathrm{T}_{2}$ measurements. Increasing noise by itself will also lead to widening of the $\mathrm{T}_{2}$ peaks (Fig.5), reflecting the uncertainty in the $\mathrm{T}_{2}$ estimation.

Regardless of the noise level, EPG captured the true FAs on average within an accuracy of $1-4^{\circ}$. Errors tended to 
bioRxiv preprint doi: https://doi.org/10.1101/2020.02.15.948976; this version posted February 17,2020 . The copyright holder for this preprint (which was not certified by peer review) is the author/funder, who has granted bioRxiv a license to display the preprint in perpetuity. It is made available under aCC-BY-NC-ND 4.0 International license.

Table 2. Influence of the choice of acquisition and selection of $T_{2, \min }$ on accurate estimation of the MW $\mathbf{T}_{2}$ and MWF. The top part of the table evaluates models with true MW $\mathrm{T}_{2}$ of $20 \mathrm{~ms}$, and the bottom half with $\mathbf{M W ~}_{2}$ of $13 \mathrm{~ms}$. Values shown correspond to $\chi^{2} / \chi_{\min }^{2}=1.02, \mathrm{nT}_{2}=120$, SNR 1000, averaged over FAs of $150^{\circ}$ â “" $180^{\circ}$. True MWF values are model dependent Model $1(21 \%$ MWF) / Model $2(11.6 \%) /$ Model $3(5 \%)$.

\begin{tabular}{|c|c|c|c|c|c|c|c|c|c|c|}
\hline \multirow[b]{2}{*}{$\mathrm{T}_{2, \min }[\mathrm{ms}]$} & \multicolumn{5}{|c|}{$\begin{array}{c}\text { MW } \mathbf{g m T}_{2}[\mathbf{m s}] \\
\text { (true value: } \mathrm{T}_{2}=20 \mathrm{~ms} \text { ) }\end{array}$} & \multicolumn{5}{|c|}{$\begin{array}{c}\text { MWF [\%] } \\
\text { (true values: } 21 \%, 11.6 \%, 5.1 \% \text { ) }\end{array}$} \\
\hline & 5 & 8 & 10 & 13 & 15 & 5 & 8 & 10 & 13 & 15 \\
\hline M1 - 32e & 8.31 & 9.95 & 11.09 & 13.66 & 15.51 & 17.19 & 16.82 & 16.67 & 16.62 & 16.95 \\
\hline$M 1-48 e$ & 18.86 & 18.78 & 18.97 & 18.95 & 19.41 & 16.80 & 16.08 & 16.16 & 16.00 & 16.39 \\
\hline$M 1-64 e$ & 12.59 & 13.39 & 13.43 & 14.66 & 16.25 & 15.34 & 14.39 & 14.44 & 14.56 & 15.58 \\
\hline M2 - 32e & 10.97 & 11.98 & 12.94 & 14.38 & 15.73 & 9.61 & 7.66 & 7.23 & 6.95 & 6.73 \\
\hline$M 2-48 e$ & 17.63 & 17.71 & 17.73 & 17.72 & 18.29 & 4.57 & 4.39 & 5.18 & 4.84 & 4.64 \\
\hline$M 2-64 e$ & 11.17 & 11.20 & 11.40 & 13.60 & 15.54 & 7.87 & 6.94 & 6.82 & 7.01 & 7.31 \\
\hline M3 - 32e & 6.16 & 8.58 & 10.40 & 13.28 & 15.50 & 1.82 & 1.72 & 1.48 & 1.33 & 1.24 \\
\hline M3 - 48e & 20.87 & 20.69 & 21.49 & 21.36 & 21.21 & 3.70 & 3.20 & 3.01 & 2.36 & 2.02 \\
\hline \multirow[t]{2}{*}{ M3 - 64e } & 5.47 & 8.30 & 10.05 & 13.13 & 15.00 & 2.75 & 1.73 & 1.28 & 1.09 & 0.95 \\
\hline & \multicolumn{5}{|c|}{$\begin{array}{c}\text { MW } \mathbf{g m T}_{2}[\mathbf{m s}] \\
\text { (true value: } \mathrm{T}_{2}=13 \mathrm{~ms} \text { ) }\end{array}$} & \multicolumn{5}{|c|}{$\begin{array}{c}\text { MWF [\%] } \\
\text { (true values: } 21 \%, 11.6 \%, 5.1 \% \text { ) }\end{array}$} \\
\hline $\mathrm{T}_{2, \min }[\mathrm{ms}]$ & 5 & 8 & 10 & 13 & 15 & 5 & 8 & 10 & 13 & 15 \\
\hline M1 - 32e & 7.35 & 9.14 & 10.81 & 13.57 & 15.31 & 23.26 & 19.14 & 18.07 & 18.02 & 18.44 \\
\hline$M 1-48 e$ & 11.44 & 12.37 & 13.22 & 14.58 & 15.94 & 21.74 & 20.24 & 19.95 & 19.76 & 20.01 \\
\hline M1 - 64e & 10.02 & 11.80 & 12.44 & 14.04 & 15.78 & 18.54 & 15.72 & 15.61 & 16.31 & 17.36 \\
\hline$M 2-32 e$ & 7.49 & 8.58 & 10.22 & 13.13 & 15.11 & 14.80 & 11.95 & 10.30 & 8.93 & 8.52 \\
\hline$M 2-48 e$ & 11.72 & 11.76 & 11.83 & 13.48 & 15.36 & 12.49 & 12.54 & 12.49 & 12.41 & 12.55 \\
\hline M2 - 64e & 7.18 & 8.83 & 11.12 & 13.71 & 15.50 & 11.45 & 10.93 & 10.78 & 11.07 & 11.34 \\
\hline M3 - 32e & 5.90 & 8.44 & 10.11 & 13.05 & 15.06 & 7.79 & 5.40 & 4.70 & 4.05 & 3.79 \\
\hline$M 3-48 e$ & 7.88 & 9.02 & 11.58 & 14.03 & 15.57 & 3.47 & 1.81 & 1.42 & 1.15 & 0.93 \\
\hline M3 - 64e & 5.68 & 8.43 & 10.31 & 13.07 & 15.04 & 4.46 & 2.98 & 2.44 & 1.85 & 1.49 \\
\hline
\end{tabular}

be larger at lower FAs and lower decay curve SNRs. FAs at $180^{\circ}$ appeared to be less accurately estimated. This is in part due to the EPG estimation limit of FAs $<180^{\circ}$, so that FAs will always be underestimated at this limit. Moreover, the trigonometric relationship between signal loss and FA plateaus at $180^{\circ}$, making the identification of the correct FA more challenging. Stimulated artifacts are, however, very small at FAs between $165^{\circ}$ and $180^{\circ}$.

Although it is important to compute the actual FAs and characterize stimulated echo artifacts in the $\mathrm{T}_{2}$ decay curves, EPG adds to the computational post-processing time. Replacing the FA estimation by EPG with acquired FA maps could lessen the required processing time. FA maps are typically acquired at a lower spatial resolution than multi-echo $\mathrm{T}_{2}$ data, as $\mathrm{B}^{+}$is assumed to be spatially slowly varying. Using spatial constraints on $\mathrm{T}_{2}$ distributions and FAs across anatomical and pathological structures, as recently described [65], has the potential to improve noise robustness for multi-component $\mathrm{T}_{2}$-mapping.

We want to emphasize again that EPG does not reverse signal loss due to low FAs or the resulting underestimation of the MWF. Thus, improving B1 ${ }^{+}$homogeneity, such that refocusing FAs are near $180^{\circ}$, should be considered a priority. Greater $\mathrm{B}^{+}$homogeneity can be achieved by dielectric pads or parallel excitation by multi-element transceiver arrays. At $3 \mathrm{~T}$, underestimations in MWF may be considered less significant than at higher field strengths, where greater $\mathrm{B} 1^{+}$ inhomogeneity is likely to impose larger spatial variations in MWF. However, as the combination of FA and noise, i.e. the SNRest, will be the determining factor for the MWF estimation, systematic underestimations in MWF measurements may be alleviated as increased SNR may make up for greater B1 ${ }^{+}$ variations at higher field strength. Even more, SNR profiles of multi-channel receive coils, which provide greatest SNR near the edge of the head, oppose the typical $\mathrm{B} 1^{+}$profile. Thus, these coils may avoid the discussed underestimations. Further work is needed to explore $\mathrm{B}^{+}$penalties as well as acquisition strategies at $7 \mathrm{~T}$ that can appropriately capture the shorter $\mathrm{T}_{2}$ decay of MW within specific absorption rate (SAR) limits.

Regularization. Although regularization is useful for resolving multi-components of the $\mathrm{T}_{2}$ distribution in the presence of noise, it comes at the cost of underestimating the MWF. We also noted that the IEW $\mathrm{gmT}_{2}$ time shortened with increasing regularization, albeit underestimations were less than $1 \mathrm{~ms}$ from the true value $44 . \chi^{2}$ constraints should only be applied over a narrow range that ensures accurate detection of multiple $\mathrm{T}_{2}$ components [42]. Increasing the "energy" constraint, i.e. enforcing greater smoothing by Tikhonov regularization, widens and subsequently merges different water peaks, leading to shorter IEW gmT 2 and reduced apparent MWF. As the coalesced peak becomes even wider, it can partly extend into the a priori defined short $\mathrm{T}_{2}$ interval, increasing measured MWF. Other regularization approaches have focused on data denoising [66] or used spatial constraints for handling of noisy data [65,67-69]. Although these methodologies yield visually appealing results, the impact of regularization should be carefully evaluated. As discussed, noise cannot always be distinguished from decay curve alterations due to stimulated echoes. Moreover, voxels of relatively low myelin content may appear noisy and residual myelin signal may be falsely removed. Spatial regularization may also have limited success for smaller 
tracts, where partial volume related underestimations in the MWF may propagate into the region-of-interest.

Other methodologies for mapping of myelin water. Different myelin water imaging techniques have been reviewed by AlonsoOrtiz et al.[70]. Multi-echo gradient-echo imaging has gained popularity for multi-compartmental fitting of $\mathrm{T}_{2}{ }^{*}$ decay data $[71,72]$. Despite the simpler and faster acquisition and lower SAR, increased sensitivity to static field inhomogeneities [73] and physiological noise [74] have made it challenging to robustly obtain $\mathrm{T}_{2}{ }^{*}$ myelin maps comparable to those obtained using spin-echo based techniques $[71,75]$. Importantly, while NNLS17 enables determination of an unlimited and unknown number of $\mathrm{T}_{2}$ components [16], most $\mathrm{T}_{2}{ }^{*}$-based techniques assume a fixed number of water compartments, usually two or three [72,76-78]. Currently, no NNLS algorithm exists that can separate the $\mathrm{T}_{2}{ }^{*}$ magnitude and frequency offsets that need to be modelled for an unknown number of signal components. A priori imposition of the number of water pools may hamper the use of these techniques and other modelbased approaches [79] in pathological cases, where changes in $\mathrm{T}_{2}$ and additional water pools have been reported $[23,36,80]$. In this work, only the multi-component $\mathrm{T}_{2}$ acquisition and NNLS analysis were considered, although other acquisition types for myelin water imaging have been proposed [81-83] and different analysis techniques may be employed $[84,85]$. To date, most of these approaches lack thorough histopathological validation and some are known to depend on the presence of magnetization exchange $[86,87]$.

$\mathbf{T}_{2, \min }$, MW $\mathbf{T}_{2}$ and MWF. Using NNLS, MW $\mathrm{T}_{2}$ may be inaccurately estimated in the presence of noise as the $\mathrm{MW} \mathrm{gmT}_{2}$ computation depends on $\mathrm{T}_{2, \min }$ and acquisition echo spacing. Typically, MW $\mathrm{gmT}_{2}$ will reach a stable solution if $\mathrm{T}_{2, \min } \leq$ MW $T_{2}$, i.e. when the short $T_{2}$ peak is fully captured. Note that the MW $\mathrm{T}_{2}$ is currently not regarded as having clinical relevance. Our observation of stable MWF even in the presence of changing $\mathrm{MW} \mathrm{gmT}_{2}$ (Tab. 2) further supports the use of MWF over $\mathrm{MW} \mathrm{gmT}$. All dependencies are summarized in Table 3.

We observed that the MW peak was best captured if $\mathrm{T}_{2, \min }$ was somewhat shorter than TE1 and shorter or equal to the $\mathrm{MW} \mathrm{T}_{2}$ in order to reproduce the true MWF. Choosing $\mathrm{T}_{2, \min }$ much lower than TE1 resulted in artifactually high MWF values due to noise in the first data points. Interestingly, longer $\mathrm{MW} \mathrm{T}_{2}$ time did not necessarily result in more accurate $\mathrm{gmT}_{2}$ and MWF values, despite both $\mathrm{T}_{2, \min }$ and the acquisition TE1 being sufficiently short to capture the MW signal. Previous work suggested that longer $\mathrm{MW} \mathrm{T}_{2}$ may require a longer first TE to obtain optimal SNR for the description of the water pools [41]. This is in line with our observations, suggesting that the optimal TE for MWI may need to be close to the MW $\mathrm{T}_{2}$.

Hardware restrictions make it difficult to accurately determine very short $T_{2}$ times as echo spacing is limited in current acquisitions. Because the in vivo $\mathrm{MW} \mathrm{T}_{2}$ is unknown, further work is needed to determine the relevance of $\Delta \mathrm{TE}$ in accurately estimating the MWF. The increased number of echoes necessary with shorter $\Delta \mathrm{TE}$ will require longer TR to comply with SAR restrictions, possible posing a limit on measurement time. Undersampling approaches for spatial encoding, such as compressed sensing $[88,89]$, may help to offset such limits.
Finally, one fixed set of $T_{2}$ boundaries and parameters is typically chosen, which is believed to characterize the IEW and MW pools on average. Note that we did not discuss the $\mathrm{T}_{2}$ cutoff time here that separates thesewater pools. This parameter was well established in our simulations, but typically needs to be determined from the $T_{2}$ distributions. As shown, single voxel MWF computations in vivo are challenging and should be approached with caution as noise and natural variations in myelin across the WM affect the MWF computation. Voxelbased average MWF measures are most commonly performed. They provide better reproducibility than region-based analyses, which would yield only a single regional MWF $[44,60]$. Across different $\mathrm{MW} \mathrm{T}_{2}$ times, in the presence of noise and due to imperfect refocusing FAs, we found that the true MWF can be estimated at $0.13-4$ percentage point deviation from the true value. Our simulations suggest that in vivo MWF measurements are reproducible [90], albeit underestimated. Reducing $\mathrm{T}_{2, \min }$ below the first $\mathrm{TE}$ appears to reasonably recover some signal lost due to regularization and FA imperfections. For comparison of data from different sites and different acquisition protocols, average SNRest and or FAs may need to be reported to assess MWF differences.

Limitations. The translation of our observations to in vivo scenarios is skewed by our limited knowledge of the true $\mathrm{T}_{2}$ distribution. We attempted to cover a wide range of acquisition and analysis parameters, relevant to the estimation of MWF. We did not simulate non-equidistant refocusing pulse schemes, previously proposed to better capture long $\mathrm{T}_{2}$ components [43], and also limited our simulations to pure spin-echo $\mathrm{T}_{2}$ decays, rather than the gradient and spin-echo acquisition currently used [58]. Non-uniform echo spacing implies a non-linear increase in refocusing pathways, greatly prolonging the computation of all magnetization states with EPG [7]. It is thus not commonly used. Computational time for EPG remains manageable if the echo spacing is changed by multiples of TE. Only Gaussian noise was investigated, as other noise patterns, such as Rician noise, have been described to affect MWF measurements similarly [44]. We chose Gaussian noise, because it is predominantly present in the earlier echoes that capture the rapid signal decay of the MW compartment. The present Bloch simulation ignored effects such as diffusion or exchange [91,92]. In the presence of exchange, an MWF decrease may be associated with a decrease in the IEW $\mathrm{gmT}_{2}$ [93]. Such exchange-associated shift in IEW $\mathrm{gmT}_{2}$ would be larger than what we observed here by altering acquisition and post-processing parameters [94]. We did not cover scenarios with MWF close to zero, as might be the case in neonates, completely demyelinated MS plaques or gray matter [95]. The created MWF scenarios only differed in the number of myelin bilayers, but kept the thickness or spacing of individual sheaths unchanged. Such changes, however, might occur due to swelling or vacuolization. This simplified model geometry created realistic water pool fractions and permits incorporating the above described parameters in the future. Although the pool fractions were the determining factor in this work, less so the actual geometry and distribution of the myelinated axons, the chosen setup allowed us to compute field inhomogeneities [96] and assign different compartmental resonance frequencies, which have been described in the literature. However, without modeling of diffusion, central k-space echoes will only minimally be affected. Finally, our 
bioRxiv preprint doi: https://doi.org/10.1101/2020.02.15.948976; this version posted February 17, 2020. The copyright holder for this preprint (which was not certified by peer review) is the author/funder, who has granted bioRxiv a license to display the preprint in perpetuity. It is made available under aCC-BY-NC-ND 4.0 International license.

Table 3. Summary of the investigated outcome measures and their dependence on $\mathbf{n T}_{2}$, regularization and the relationship between $\mathrm{MW}_{2}$, $\mathbf{T}_{2, \min }$ and acquisition echo spacing $\Delta \mathrm{TE}$. Average differences from the true values are indicated for available data. NI: not investigated. pp: percentage points

\begin{tabular}{|c|c|c|c|c|c|}
\hline & $\mathrm{nT}_{2}$ & $\chi^{2} / \chi_{\min }^{2}$ & $\mathrm{MW} \mathrm{T}_{2}$ & $\mathrm{~T}_{2, \min }$ & $\mathrm{TE}_{1}$ and $\Delta \mathrm{TE}$ \\
\hline FA estimation & $\sim 1^{\circ}$ & & $\begin{array}{l}\text { Non-systematic vari- } \\
\text { ations }\end{array}$ & $\mathrm{NI}$ & $\begin{array}{l}\text { In some cases, im- } \\
\text { proved with shorter } \\
\mathrm{TE}_{1} / \Delta \mathrm{TE}\end{array}$ \\
\hline IEW $\operatorname{gmT}_{2}$ & $\sim 1 \mathrm{~ms}$ & $\begin{array}{l}\text { Decreasing with in- } \\
\text { creasing } \chi^{2}\end{array}$ & $\begin{array}{ll}\text { Overestimated } & \text { if } \\
\mathrm{T}_{2, \min }>\mathrm{MW} \mathrm{\textrm {T } _ { 2 }} \\
\text { Underestimated } \\
\mathrm{T}_{2, \min }<\mathrm{MW} \mathrm{T}_{2}\end{array}$ & $\begin{array}{l}<3 \mathrm{~ms} \\
\text { Most accurate: } \\
\mathrm{T}_{2, \min } \sim \mathrm{MW} \mathrm{T}_{2}\end{array}$ & No difference \\
\hline $\mathrm{MW} \mathrm{gmT}_{2}$ & $<1 \mathrm{~ms}$ & $\begin{array}{l}\text { Increasing with in- } \\
\text { creasing } \chi^{2}\end{array}$ & & $\begin{array}{l}\text { Stable, but underes- } \\
\text { timated, if } \mathrm{T}_{2, \min }< \\
\mathrm{MW} \mathrm{T}_{2}\end{array}$ & $\begin{array}{l}\text { In some cases, im- } \\
\text { proved with shorter } \\
\mathrm{TE}_{1} / \Delta \mathrm{TE}\end{array}$ \\
\hline MWF & NI & $\begin{array}{l}\text { Decreasing initially, } \\
\text { then increasing with } \\
\chi^{2}\end{array}$ & $\begin{array}{l}\text { Stable if } \mathrm{MW} \mathrm{T}_{2}> \\
\mathrm{TE} \\
\text { Remains stable if } \\
\mathrm{MW} \mathrm{T}_{2}>(\mathrm{TE}-2 \mathrm{~ms})\end{array}$ & $\begin{array}{l}\text { 5pp variation } \\
\text { Only } 2 \mathrm{pp} \text { if } \mathrm{T}_{2, \min } \\
>\mathrm{TE} \text {, but underes- } \\
\text { timated }\end{array}$ & $\begin{array}{l}\text { Shorter } \Delta \mathrm{TE} \text { can im- } \\
\text { prove consistency in } \\
\text { MWF estimation }\end{array}$ \\
\hline
\end{tabular}

Summary

- $\mathrm{nT}_{2}=40$ - reasonable unless significant signal variation or more peaks are expected at short $\mathrm{T}_{2}$

- $\chi^{2} / \chi_{\min }^{2}=1.02-$ SNR dependent, should typically not be chosen higher

- $\operatorname{gm~} \mathrm{T}_{2}$ times - most accurate, if $\mathrm{T}_{2, \mathrm{~min}} \leq \mathrm{MW} \mathrm{T}_{2}$, but with $\mathrm{MW} \mathrm{T}_{2}$ unknown

- $\mathrm{MWF}$ - most accurate, if $\mathrm{T}_{2, \mathrm{~min}} \leq \mathrm{TE}_{1}$, shorter within a few $\mathrm{ms}(1-2 \mathrm{~ms})$

simulations allowed generation of decay curves with stimulated echo artifacts independent of the EPG, which was used to analyze the decay curves.

\section{Conclusions}

The selection of shorter echo spacing and an appropriate $\mathrm{T}_{2, \text { min }}$ improved the estimation of the amount of short $\mathrm{T}_{2}$ signal. We showed by realistic simulations that voxel-based averages were able to estimate the true MWF within $0.13-$ 4 percentage points, with increasing accuracy if $\mathrm{T}_{2, \min }$ was selected slightly shorter than the first echo time. The number of $\mathrm{T}_{2}$ times used to compute the $\mathrm{T}_{2}$ distributions hardly affected the results. By contrast, increasing regularization should be applied with caution. Reporting the estimated SNR and average FA for specific regions of interest may help researchers to assess the systematic underestimation in MWF incurred due to the dependence of the $\mathrm{T}_{2}$ signal decay on noise and $\mathrm{B}^{+}$inhomogeneities. Advances in MR hardware may overcome current limitations in multi-echo $\mathrm{T}_{2}$ acquisition schemes to map the MWF more accurately.

\section{References}

[1] Hahn EL. Nuclear induction due to free Larmor precession. Phys Rev 1950;77:297.

[2] Hahn EL. Spin echoes. Phys Rev 1950;80(4):580-594.

[3] Carr HY, Purcell EM. Effects of diffusion on free precession in nuclear magnetic resonance experiments. Phys Rev 1954;94:630-638.

[4] Meiboom S, Gill D. Modified spin-echo method for measuring nuclear relaxation times. Rev Sci Instrum 1958;29:688-691.

[5] Hennig J, Nauerth A, Friedburg H. RARE Imaging: A fast imaging method for clinical MR. Magn Reson Med 1986;3:823-833.
[6] Hennig J. Multiecho imaging sequences with low refocusing flip angles. Magn Reson Med 1988;78:397-407.

[7] Hennig J. Echoes - How to generate, recognize, use or avoid them in MR-imaging sequences. Part I: Fundamental and not so fundamental properties of spin echoes. Concepts Magn Reson 1991;2:125-143.

[8] Wansapura JP, Holland SK, Dunn RS, Ball WS. NMR relaxation times in the human brain at 3.0 tesla. J Magn Reson Med 1999;9(4):531538.

[9] Stanisz GJ, Odrobina EE, Pun J, Escaravage M, Graham SJ, Bronskill MJ, Henkelman RM. T1, T2 relaxation and magnetization transfer in tissue at 3T. Magn Reson Med 2005;54(3):507-512.

[10] Mosher TJ, Dardzinski BJ. Cartilage MRI T2 relaxation time mapping: overview and applications. Semin Musculoskelet Radiol 2004;8(4):355-368.

[11] Marinelli NL, Haughton VM, Muñoz A, Anderson PA. T2 relaxation times of intervertebral disc tissue correlated with water content and proteoglycan content. Spine 2009;34(5):520-524

[12] Vasilescu V, Katona E, Simplaceanu V, Demco D. Water compartments in the myelinated nerve. III Pulsed NMR experiments. Experientia 1978;34:1443-1444.

[13] Stewart WA, MacKay AL, Whittall KP, Moore GRW, Paty DW. Spin-spin relaxation in experimental allergic encephalomyelitis. Analysis of CPMG data using a non-linear least squares method and linear inverse theory. Magn Reson Med 1993;29:767-775.

[14] Saab G, Thompson RT, Marsh GD. Multicomponent T2 relaxation of in vivo skeletal muscle. Magn Reson Med 1999;42:150-157.

[15] Xia Y, Moody JB, Alhadlaq H. Orientational dependence of T2 relaxation in articular cartilage: A microscopic MRI ( $\mu$ MRI) study. Magn Reson Med 2002;48(3):460-469.

[16] Whittall KP, MacKay AL. Quantitative interpretation of NMR relaxation data. J Magn Reson 1989;84:134-152.

[17] Lawson CL, Hanson RJ. Solving least squares problems (Vol 15). 
Siam; 1995.

[18] Menon RS, Allen PS. Application of continuous relaxation time distributions to the fitting of data from model systmes and excised tissue. Magn Reson Med 1991;20(2):214-227.

[19] MacKay A, Whittall K, Adler J, Li D, Paty D, Graeb D. In vivo visualization of myelin water in brain by magnetic resonance. Magn Reson Med 1994;31(6):673-677.

[20] Bloom M, Holmes KT, Mountford CE, Williams PG. Complete proton magnetic resonance in whole cells. J Magn Reson 1986;69:73-91. [21] Norton WT, Cammer W. Isolation and characterization of myelin. In: Myelin. Springer, Boston MA, 1984. 147-195.

[22] Laule C, Vavasour IM, Kolind SH, Li DKB, Traboulsee TL, Moore GRW, MacKay AL. Magnetic resonance imaging of myelin. Neurotherapeutics 2007;4(3):460-484.

[23] Vavasour IM, Whittall KP, MacKay AL, Li DKB, Vorobeychik G, Paty DW. A comparison between magnetization transfer ratios and myelin water percentages in normal and multiple sclerosis patients. Magn Reson Med 1998;40(5):763-768.

[24] Moore GRW, Leung E, MacKay AL, Vavasour IM, Whittall KP, Cover KS, Li DKB, Hashimoto SA, Oder J, Sprinkle TJ, Paty DW. A pathology-MRI study of the short-T2 component in formalin-fixed multiple sclerosis brain. Neurology 2000;55(10):1506-1510.

[25] Laule C, Kozlowski P, Leung E, Li DKB, MacKay AL, Moore GW. Myelin water imaging of multiple sclerosis at $7 \mathrm{~T}$ : correlations with histopathology. NeuroImage 2008;40(4):1575-1580.

[26] Laule C, Leung E, Li DKB, Traboulsee AL, Paty DW, MacKay AL, Moore GRW. Myelin water imaging in multiple sclerosis: quantitative correlations with histopathology. Mult Scler 2006;12(6):747-753.

[27] Möller HE, Bossoni L, Conner JR, Crichton RR, Does MD, Ward RJ, Zecca L, Zucca FA, Ronen I. Iron, myelin, and the brain: Neuroimaging meets neurobiology. Trans Neurosci 2019;42(6):384-401. [28] Birkl C, Birkl-Toeglhofer AM, Endmayr V, Höftberger R, Kasprian G, Krebs C, Haybaeck J, Rauscher A. The influence of brain iron on myelin water imaging. NeuroImage 2019;199:545-552.

[29] Conner JR. Iron acquisition and expression of iron regulatory proteins in the developing brain: manipulation by ethanol exposure, iron deprivation and cellular dysfunction. Dev Neurosci 1994;16:233-247.

[30] Holland BA, Haas DK, Norman D, Brant-Zawadzki M, Newton TH. MRI of normal brain maturation. Am J Neuroradiol AJNR 1986;7(2):201-208.

[31] Deoni SCL, Dean III DC, O'Muircheartaigh J, Dirks H, Jerskey BA. Investigating white matter development in infancy and early childhood using myelin water fraction and relaxation time mapping. NeuroImage 2012;63(3):1038-1053.

[32] Su P, Kuan C-C, Kaga K, Sano M, Mima K. Myelination progression in language-correlated regions in brain of normal children determined by quantitative MRI assessment. Int $\mathrm{J}$ Pediatr Otorhinolaryngol 2008;72(12):1751-1763.

[33] Wright AD, Jarrett M, Vavasour I, Shahinfard E, Kolind S, van Donkelaar P, Taunton J, Li D, Rauscher A. Myelin water fraction is transiently reduced after a single mild traumatic brain injury a prospective cohort study in collegiate hockey players. PLoS One 2016;11(2):e0150215.

[34] Billiet T, Vandenbulcke M, Mädler B, Peeters R, Dhollander T, Zhang H, Deprez S, Van den Bergh BR, Sunaert S, Emsell L. Age-related microstructural differences quantified using myelin water imaging and advanced diffusion MRI. Neurobiol Aging 2015;36(6):2107-2121.

[35] Gunning-Dixon FM, Brickman AM, Cheng JC, Alexopoulos GS. Aging of cerebral white matter: a review of MRI findings. Int J Geriatr Psychchiatry 2009;24(2):109-117.

[36] Whittall K, MacKay A, Li DKB, Vavasour IM, Jones CK, Paty DW.
Normal-appearing white matter in multiple sclerosis has heterogeneous, diffusely prolonged T2. Magn Reson Med 2002;47(2):403-408.

[37] Shatil AS, Uddin MN, Matsuda KM, Figley CR. Quantitative ex vivo MRI changes due to progressive formalin fixation in whole human brain specimens: Longitudinal characterization of diffusion, relaxometry, and myelin water fraction measurements at 3T. Front Med 2018; 5:31.

[38] Bonilla I, Snyder RE. Transverse relaxation in rat optic nerve. NMR Biomed 2007;20(2):113-120.

[39] Russel-Schulz B, Laule C, Li DKB, MacKay AL. What causes the hyperintense $\mathrm{T} 2$-weighting and increased short $\mathrm{T} 2$ signal in the corticospinal tract? Magn Reson Imaging 2013;31(3):329-335.

[40] Dortch RD, Harkins KD, Juttukonda MR, Gore JC, Does MD. Characterizing inter-compartmental water exchange in myelinated tissue using relaxation exchange spectroscopy. Magn Reson Med 2013;70(5):1450-1459.

[41] Dula AN, Gochberg DF, Does MD. Optimal echo spacing for multi-echo imaging measurements of Bi-exponential T2 relaxation. J Magn Reson 2009;196(2):149-156.

[42] Graham SJ, Stanchev PL, Bronskill MJ. Criteria for analysis of multicomponent tissue T2 relaxation data. Magn Reson Med 1996;35(3):370-378.

[43] Skinner MG, Kolind SH, MacKay AL. The effect of varying echo spacing within a multiecho acquisition: better characterization of long T2 components. Magn Reson Imaging 2007;25:840-847.

[44] Bjarnason TA, McCreary CR, Dunn JF, Mitchell JR. Quantitative T2 analysis: The effects of noise, regularization, and multivoxel approaches. Magn Reson Med 2010;63:212-217.

[45] Prasloski T, Mädler B, Xiang Q-S, MacKay A, Jones C. Applications of stimulated echo correction to multicomponent $\mathrm{T} 2$ analysis. Magn Reson Med 2012;67(6):1803-1814.

[46] MacKay A, Laule C, Vavasour I, Bjarnason T, Kolind S, Mädler B. Insights into brain microstructure from the T2 distribution. Magn Reson Imaging 2006;24(4):515-525.

[47] Labadie C, Lee JH, Rooney WD, Jarchow S, Aubert-Frécon M, Springer Jr CS, Möller HE. Myelin water mapping by spatially regularized longitudinal relaxographic imaging at high magnetic fields. Magn Reson Med 2014;71(1):375-387.

[48] Barta R, Kalantari S, Laule C, Vavasour IM, MacKay AL, Michal CA. Modeling T1 and T2 relaxation in bovine white matter. J Magn Reson 2015;259;56-67.

[49] Marques JP, Bowtell R. Application of a Fourier-based method for rapid calculation of field inhomogeneity due to spatial variation of magnetic susceptibility. Concepts Magn Reson 2005;25B:65-78.

[50] He X, Yablonskiy DA. Biophysical mechanisms of phase contrast in gradient echo MRI. Proc Natl Acad Sci USA 2009;106(32):13558-13563. [51] Morell P, Quarles RH. Characteristic composition of myelin. In: Basic Neurochemistry: Molecular, cellular and medical aspects. 6th edition. Philadelphia, Lippincott-Raven; 1999.

[52] Lee H, Nam Y, Lee H-J, Hsu JJ, Henry RG, Kim DH. Improved three-dimensional multi-echo gradient echo based myelin water fraction mapping with phase related artifact correction. NeuroImage 2018;169:1-10.

[53] Nam Y, Lee J, Hwang D, Kim D-H. Improved estimation of myelin water fraction using complex model fitting. NeuroImage 2015;116:214-221.

[54] Alonso-Ortiz E, Levesque IR, Pike GB. Impact of magnetic susceptibility anisotropy at $3 \mathrm{~T}$ and $7 \mathrm{~T}$ on $\mathrm{T} 2 *$-based myelin water fraction imaging. NeuroImage 2017;182:370-378.

[55] Morrison C, Henkelman RM. A model for magnetization transfer in tissues. Magn Reson Med 1995;33(4):475-482. 
[56] Wilhelm MJ, Ong HH, Wehrli SL, Li C, Tsai PH, Hackney DB, Wehrli FW. Direct magnetic resonance detection of myelin and prospects for quantitative imaging of myelin density. Proc Natl Acad Sci USA 2012;109(24):9605-9610.

[57] Does MD, Beaulieu C, Allen PS, Snyder RE. Multi-component T1 relaxation and magnetisation transfer in peripheral nerve. Magn Reson Imaging 1998;16(9):1033-1041.

[58] Prasloski T, Rauscher A, MacKay AL, Hodgson M, Vavasour IM, Laule C, Mädler B. Rapid whole cerebrum myelin water imaging using a 3D GRASE sequence. NeuroImage 2012;63(1):533-539.

[59] Zhang J, Vavasour I, Kolind SH, Baumeister B, Rauscher A, MacKay AL. Advanced myelin water imaging techniques for rapid data acquisition and long T2 component measurements. Proc Intl Soc Mag Reson Med 23;2015, p. 824.

[60] Meyers SM, Laule C, Vavasour IM, Kolind SH, Mädler B, Tam R, Traboulsee AL, Lee J, Li DKB, MacKay AL. Reproducibility of myelin water fraction analysis: a comparison of region of interest and voxelbased analysis methods. Magn Reson Imaging 2009;27(8):1096-1103.

[61] Oh J, Han ET, Lee MC, Nelson SJ, Pelletier D. Multislice brain myelin water fractions at $3 \mathrm{~T}$ in multiple sclerosis. J Neuroimaging 2007;17(2):156-163.

[62] Bro R and De Jong S. A fast non-negativity-constrained least squares algorithm. J Chemometrics 1997;11:393-401.

[63] Provencher SW. A constrained regularization method for inverting data represented by linear algebraic or integral equations. Comput Phys Commun 1982;27(3):213-227.

[64] Whittall KP, MacKay AL, Graeb DA, Nugent RA, Li DK, Paty DW. In vivo measurements of $\mathrm{T} 2$ distributions and water contents in normal human brain. Magn Reson Med 1997;37(1):34-43.

[65] Kumar D, Hariharan H, Faizy TD, Borchert P, Siemonsen S, Fiehler J, Reddy R, Sedlacik J. Using 3D spatial correlations to improve the noise robustness of multi component analysis of 3D multi echo quantitative T2 relaxometry data. NeuroImage 2018;178:583-601.

[66] Does MD, Olesen JL, Harkins KD, Serradas-Duarte T, Gochberg DF, Jespersen SN, Shemesh N. Evaluation of principal component analysis image denoising on multi-exponential MRI relaxometry. Magn Reson Med 2019;81:3503-3514.

[67] Hwang D, Du YP. Improved myelin water quantification using spatially regularized non-negative least squares algorithm. J Magn Reson Imaging 2009;30:203-208.

[68] Yoo Y and Tam R. Non-local spatial regularization of MRI T2 relaxation images for myelin water quantification. In: Mori $\mathrm{K}$, et al., (eds.) Medical Image Computing \& Computer-Assisted Intervention - MICCAI 2013, Nagoya, Japan, vol 8149, Berlin, Heidelberg: Springer-Verlag, p. 614-621.

[69] Yoo Y, Prasloski T, Vavasour IM, MacKay A, Traboulsee AL, Li DKB, Tam RC. Fast computation of myelin maps from MRI T2 relaxation data using multicore $\mathrm{CPU}$ and graphics card parallelization. J Magn Reson Imaging 2015;41:700-707.

[70] Alonso-Ortiz E, Levesque IR, Pike GB. MRI-based myelin water imaging: a technical review. Magn Reson Med 2015;73(1):70-81.

[71] Lenz C, Klarhofer M, Scheffler K. Feasibility of in vivo myelin imaging using 3D multigradient-echo pulse sequences. Magn Reson Med 2012;68(2):523-528.

[72] Sati P, van Gelderen P, Silva A, Reich DS, Merkle H, De Zwart JA, Duyn JH. Micro-compartment specific T2* relaxation in the brain. NeuroImage 2013;77:268-278.

[73] Alonso-Ortiz E, Levesque IR, Paquin R, Pike GB. Field inhomogeneity correction for gradient echo myelin water fraction imaging. Magn Reson Med 2017;78(1):49-57.

[74] Nam Y, Kim DH, Lee J. Physiological noise compensation in gradient-echo myelin water imaging. NeuroImage 2015;120:345-349. [75] Alonso-Ortiz E, Levesque IR, Pike GB. Multi-gradient-echo myelin water fraction imaging: Comparison to the multi-echo-spin-echo technique. Magn Reson Med 2018;79(3):1439-1446.

[76] Andrews T, Lancester JL, Dodd SJ, Contreras-Sesvold C, Fox PT. Testing the three-pool white matter model adapted for use with T2 relaxometry. Magn Reson Med 2005;54:449-454.

[77] Du YP, Chu R, Hwang D, Brown MS, Kleinschmidt-DeMasters BK, Singel D, Simon JH. Fast multislice mapping of the myelin water fraction using multicompartment analysis of $\mathrm{T} 2 *$ decay at $3 \mathrm{~T}$ : A preliminary postmortem study. Magn Reson Med 2007;58(5):865-870.

[78] van Gelderen P, De Zwart JA, Lee J, Sati P, Reich DS, Duyn JH. Nonexponential T2* decay in white matter. Magn Reson Med 2012;67(1):110-117.

[79] Warntjes M, Engström M, Tisell A, Lundberg P. Modeling the presence of myelin and edema in the brain based on multi-parametric quantitative MRI. Front Neurol 2016;7:16.

[80] Laule C, Vavasour IM, Mädler B, Kolind SH, Sirrs SM, Brief EE, Traboulsee AL, Moore GRW, Li DKB, MacKay AL. MR evidence of long T2 water in pathological white matter. J Magn Reson Imaging 2007;26(4):1117-1121.

[81] Oh J, Han ET, Pelletier D, Nelson SJ. Measurement of in vivo multi-component $\mathrm{T} 2$ relaxation times for brain tissue using multi-slice T2 prep at 1.5 and 3 T. Magn Reson Med 2006;24(1):33-43.

[82] Nguyen TD, Wisnieff C, Cooper MA, Kumar D, Raj A, Spincemaille P, Wang Y, Vartanian T, Gauthier SA. T2prep three-dimensional spiral imaging with efficient whole brain coverage for myelin water quantification at 1.5 tesla. Magn Reson Med 2012;67(3):614-621.

[83] Deoni SCL, Rutt BK, Arun T, Pierpaoli C, Jones DK. Gleaning multicomponent $\mathrm{T} 1$ and $\mathrm{T} 2$ information from steady-state imaging data. Magn Reson Med 2008;60:1372-1387.

[84] Bouhrara M, Spencer RG. Rapid simultaneous high-resolution mapping of myelin water fraction and relaxation times in human brain using BMC-mcDESPOT. NeuroImage 2017;147:800-811.

[85] Kumar D, Nguyen TD, Gauthier SA, Raj A. Bayesian algorithm using spatial priors for multiexponential T2 relaxometry from multiecho spin echo MRI. Magn Reson Med 2012;68(5):1536-1543.

[86] West DJ, Teixeira RPAG, Wood TC, Hajnal JV, Tournier JD, Malik SJ. Inherent and unpredictable bias in multi-component DESPOT myelin water fraction estimation. NeuroImage 2019;195:78-88.

[87] Zhang J, Kolind SH, Laule C, MacKay AL. How does magnetization transfer influence mcDESPOT results? Magn Reson Med 2015;74(5):1327-1335.

[88] Lustig M, Donoho D, Pauly JM. Sparse MRI: The application of compressed sensing for rapid MR imaging. Magn Reson Med 2007;58(6):1182-1195.

[89] Liang D, Liu B, Wang J, Ying L. Accelerating SENSE using compressed sensing. Magn Reson Med 2009;62(6):1574-1584.

[90] Meyers SM, Vavasour IM, Mädler B, Harris T, Fu E, Li DKB, Traboulsee AL, MacKay AL, Laule C. Multicenter measurements of myelin water fraction and geometric mean T2: intra-and intersite reproducibility. J Magn Reson Imaging 2013;38(6):1445-1453.

[91] Woessner DE. Effects of diffusion in nuclear magnetic resonance spin-echo experiments. J Chem Phys 1961;34:2057-2061.

[92] Harkins KD, Dula AN, Does MD. Effect of intercompartmental water exchange on the apparent myelin water fraction in multiexponential T2 measurements of rat spinal cord. Magn Reson Med 2012;67(3):793-800.

[93] Edzes HT and Samulski ET. The measurement of cross-relaxation effects in the proton NMR spin-lattice relaxation of water in biological systems: hydrated collagen and muscle. J Magn Reson 1978;31(2):207- 
229.

[94] Dula AN, Gochberg DF, Valentine HL, Valentine WM, Does MD. Multiexponential T2, magnetization transfer, and quantitative histology in white matter tracts of rat spinal cord. Magn Reson Med 2010;63(4):902-909.

[95] Lucchinetti C, Brück W, Parisi J, Scheithauer B, Rodriguez M, Lassmann H. Heterogeneity of multiple sclerosis lesions: implications for the pathogenesis of demyelination. Ann Neurol 2000;47:707-717.

[96] Majumdar S, Orphanoudakis SC, Gmitro A, O'Donnell M, Gore
JC. Errors in the measurements of T2 using multiple-echo MRI techniques. II. Effects of static field inhomogeneities. Magn Reson Med 1986;3:562-574.

ACKNOWLEDGMENTS. This work was funded by the Natural Sciences and Engineering Research Council of Canada and the National Multiple Sclerosis Society. AR is funded by Canada Research Chairs. 
bioRxiv preprint doi: https://doi.org/10.1101/2020.02.15.948976; this version posted February 17,2020 . The copyright holder for this preprint (which was not certified by peer review) is the author/funder, who has granted bioRxiv a license to display the preprint in perpetuity. It is made available under aCC-BY-NC-ND 4.0 International license.
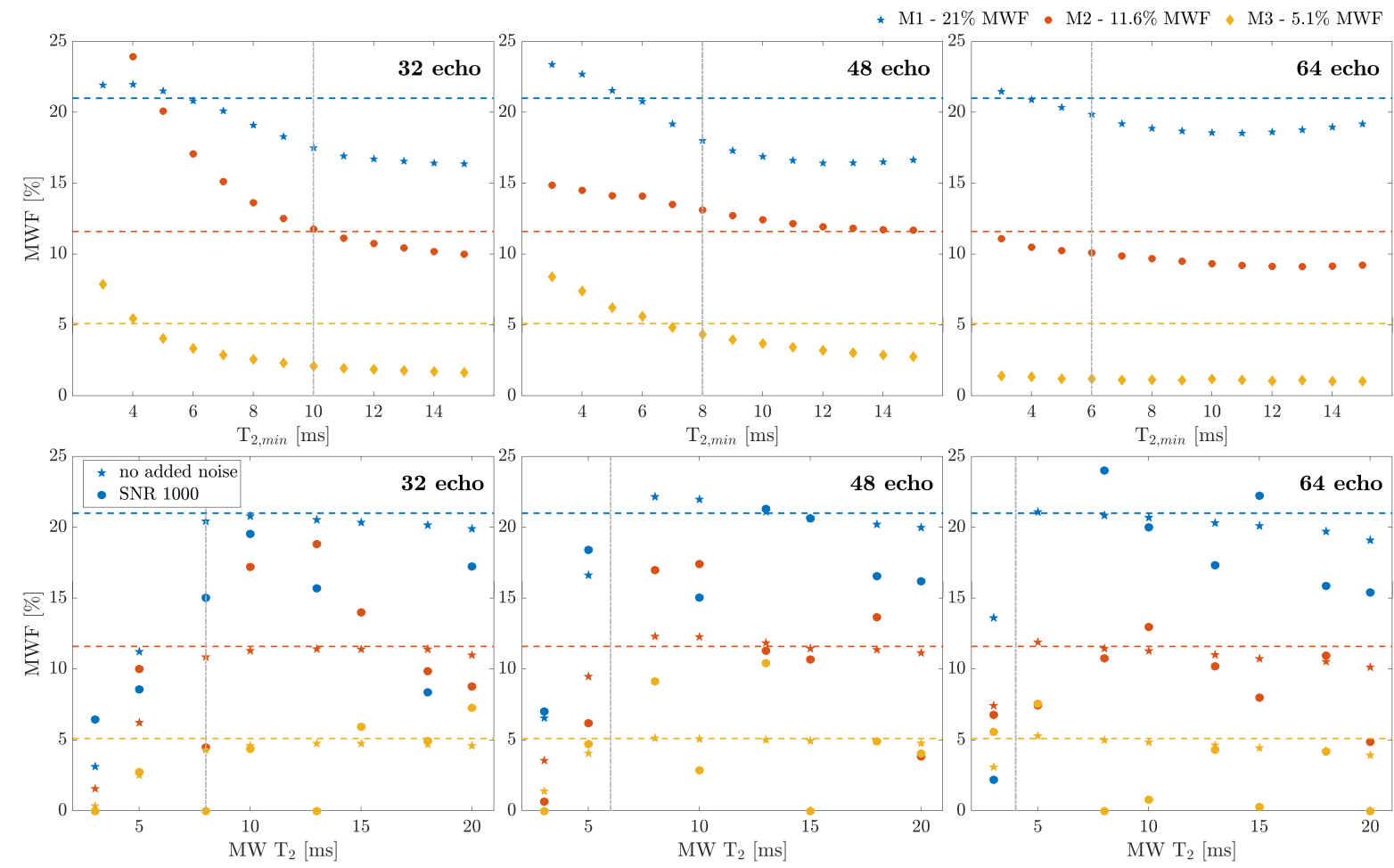

Fig. 8. Supplementary Figure (full version of Figure 7): Mean MWF estimates relative to the true values at different $T_{2}, \min$ (top) and MW $T_{2}$ times (bottom), at SNR $=$ $1000, \chi^{2} / \chi_{\min }^{2}=1.02, \mathrm{nT2}=120$. Top row: Mean MWF averaged over different $\mathrm{MW}_{2}$ times $(15,13,10$ and $8 \mathrm{~ms})$ for different acquisition strategies at $\mathrm{FA}=170^{\circ}$. The true MWF values (21, 11.6 and $5.1 \%$ ) are shown for comparison as dashed lines. The gray, dash-dotted verticals indicate the acquisition TE, relative to $T_{2, m i n}$. The $32 e$ acquisition showed greater variations with $\mathrm{T}_{2, \text { min }}$ than the other acquisitions. Bottom row: Mean MWF values for different $\mathrm{MW}_{2}$ times computed at a specified $\mathrm{T}_{2, \text { min }}$ (gray, dash-dotted vertical line). Estimates are compared in the presence and absence of noise. Note that the x-axes differ; top row T2,min, bottom row MW $\mathrm{T}_{2}$.

Table 4. Supplementary table: Influence of different FAs and $\mathrm{T}_{2, \min }$ on the estimation of IEW $\mathbf{g m T}_{2}$ for all models using a MW $\mathrm{T}_{2}$ of 15 ms (upper section) and $\mathbf{M W ~} \mathbf{T}_{2}$ of $8 \mathrm{~ms}$ (bottom section). Values represent averages are over all $\mathbf{n} \mathbf{T}_{2}$ and $\chi^{2}=1.02$. Values shown are for Model 1 (21\% MWF) / Model $2(11.6 \%)$ / Model $3(5.1 \%)$ and the different acquisition strategies.

\begin{tabular}{|c|c|c|c|c|c|c|c|c|c|c|}
\hline \multirow[b]{2}{*}{$\mathrm{T}_{2, \min }[\mathrm{ms}]$} & \multicolumn{5}{|c|}{$\begin{array}{c}\mathrm{MW} \mathrm{gmT}_{2}[\mathrm{~ms}] \\
\text { (true value: } \mathrm{T}_{2}=20 \mathrm{~ms} \text { ) }\end{array}$} & \multicolumn{5}{|c|}{$\begin{array}{c}\text { MWF [\%] } \\
\text { (true values: } 21 \%, 11.6 \%, 5.1 \% \text { ) }\end{array}$} \\
\hline & 5 & 8 & 10 & 13 & 15 & 5 & 8 & 10 & 13 & 15 \\
\hline M1 - 32e & 66.85 & 65.88 & 66.59 & 67.86 & 68.74 & 68.36 & 68.45 & 68.21 & 68.47 & 69.27 \\
\hline M1 - 48e & 65.80 & 65.85 & 66.21 & 67.44 & 68.00 & 66.82 & 66.59 & 66.84 & 67.12 & 67.70 \\
\hline M1 - 64e & 68.68 & 68.59 & 68.59 & 68.73 & 68.64 & 67.42 & 66.92 & 67.13 & 67.35 & 6768 \\
\hline M2 - 32e & 68.57 & 68.76 & 69.23 & 69.76 & 70.53 & 66.52 & 66.72 & 67.40 & 68.21 & 68.90 \\
\hline M2 - 48e & 67.24 & 67.22 & 67.54 & 68.19 & 68.45 & 64.97 & 65.13 & 65.30 & 65.71 & 65.84 \\
\hline M2 - 64e & 65.40 & 65.60 & 65.87 & 66.12 & 66.37 & 64.29 & 64.35 & 64.30 & 64.49 & 64.70 \\
\hline M3 - 32e & 68.78 & 68.81 & 68.95 & 69.14 & 69.32 & 68.55 & 68.63 & 68.74 & 68.49 & 68.53 \\
\hline M3 - 48e & 65.75 & 65.70 & 65.70 & 65.70 & 65.70 & 68.60 & 68.65 & 6866 & 68.67 & 68.66 \\
\hline \multirow[t]{2}{*}{ M3 - 64e } & 66.41 & 66.53 & 66.81 & 66.37 & 66.47 & 68.66 & 68.57 & 68.46 & 68.51 & 68.49 \\
\hline & \multicolumn{5}{|c|}{$\begin{array}{c}\mathrm{MW} \mathrm{gmT} \mathrm{gms}_{2}[\mathrm{~ms}] \\
\text { (true value: } \mathrm{T}_{2}=13 \mathrm{~ms} \text { ) }\end{array}$} & \multicolumn{5}{|c|}{$\begin{array}{c}\text { MWF [\%] } \\
\text { (true values: } 21 \%, 11.6 \%, 5.1 \% \text { ) }\end{array}$} \\
\hline $\mathrm{T}_{2, \min }[\mathrm{ms}]$ & 5 & 8 & 10 & 13 & 15 & 5 & 8 & 10 & 13 & 15 \\
\hline M1 - 32e & 65.11 & 65.77 & 66.33 & 67.10 & 67.51 & 70.98 & 71.27 & 71.50 & 72.01 & 72.02 \\
\hline M1 - 48e & 69.56 & 70.15 & 70.52 & 71.26 & 71.49 & 68.63 & 68.84 & 69.34 & 70.22 & 70.82 \\
\hline M1 - 64e & 68.74 & 69.85 & 70.44 & 71.24 & 71.67 & 68.43 & 69.44 & 70.12 & 70.94 & 71.49 \\
\hline M2 - 32e & 67.31 & 67.34 & 67.37 & 67.75 & 67.61 & 69.21 & 69.44 & 69.59 & 69.99 & 69.99 \\
\hline$M 2-48 e$ & 68.24 & 68.92 & 69.30 & 70.03 & 70.03 & 66.72 & 66.78 & 66.77 & 66.96 & 66.81 \\
\hline M2 - 64e & 68.64 & 68.68 & 69.07 & 69.73 & 69.72 & 67.19 & 67.47 & 67.73 & 68.15 & 68.23 \\
\hline M3 - 32e & 68.21 & 68.17 & 68.15 & 68.18 & 68.14 & 70.74 & 70.88 & 71.24 & 71.26 & 71.74 \\
\hline M3 - 48e & 71.12 & 71.27 & 71.41 & 71.36 & 71.25 & 69.72 & 69.76 & 69.78 & 69.75 & 69.81 \\
\hline M3 - 64e & 67.95 & 67.94 & 67.91 & 67.93 & 67.91 & 69.73 & 6979 & 69.93 & 70.03 & 69.88 \\
\hline
\end{tabular}

